\title{
THE PERFORMANCE OF A URANIUM GAS SAMPLING CALORIMETER
}

Yu. GALAKTIONOV, A. GORDEEV, Yu. GORODKOV, Yu. KAMYSHKOV, A. KLIMENTOV, A. KUNIN, V. KOUTSENKO, A. MALININ, V. MORGUNOV, V. PLYASKIN, V. POJIDAEV, A. SAVIN, V. SHEVCHENKO, E. SHUMILOV, V. SHOUTKO, E. TARKOVSKY and V. TCHUDAKOV

Institute for Theoretical and Experimental Physics, Moscow, USSR

\section{S.C.C. TING}

Massachusetts Institute of Technology, Cambridge, Massachusetts, USA

\author{
T. AZEMOON, R.C. BALL, I.D. LEEDOM * and M.J. LONGO \\ University of Michigan, Ann Arbor, Michigan, USA
}

Received 21 April 1986

\begin{abstract}
The performance of a uranium gas sampling hadron calorimeter is described. It has been observed that the hydrogen content of the gas mixture plays an important role in defining the behaviour of this type of calorimeter. The low-energy neutrons emerging from a hadron cascade are detected much more efficiently in a hydrogenous gas; thus leakage or containment of these neutrons becomes an important feature of the calorimeter setup.
\end{abstract}

\section{Introduction}

During the last few years we have been developing a uranium gas sampling calorimeter for the LEP L3 project. The first results, covering the general performance of the calorimeter, have already been published [1-3]. Here we report the results of further studies relating to the influence of the gas type and the sampling thickness on the calorimeter performance.

\section{The beam and experimental setup}

Two similar setups were used, one at the CERN super proton synchroton (SPS) beam and the other at an ITEP PS beam. The data taken at ITEP covered the lower energy range of $1-6 \mathrm{GeV}$, whereas the data from the SPS were for the wider energy range of $2-50 \mathrm{GeV}$ and will be the subject of a separate report.

The composition of the ITEP PS beam [4] is shown in fig. 1. In order to increase the electron yield, a $5 \mathrm{~mm}$ lead converter was placed near the production target. The energy spread as well as the absolute energy calibration of the electron beam were checked with a lead-glass total absorption counter which was 20 radia-

* Present address: FNAL, Batavia, Ill, USA tion lengths thick. The results are shown in fig. 2. The momentum spread of the beam was below $2 \%$.

The experimental arrangement used at ITEP is shown in fig. 3. The threshold Cherenkov counter was used to select electrons, and the $35 \mathrm{~cm}$ of iron behind the calorimeter served as a filter for muons.

\section{The calorimeter}

The calorimeter consisted of proportional chambers interleaved with $4.5 \mathrm{~mm}$ thick absorber plates made of depleted uranium, as shown in fig. 4. The surface area of the absorber plates was $50 \times 50 \mathrm{~cm}^{2}$.

The front end of the calorimeter was equipped with proportional chambers, built at the University of Michigan, which are shown schematically in fig. 5a. The chambers were made of rectangular brass tubing with inner dimensions of $6 \times 12 \mathrm{~mm}^{2}$. Each chamber contained 40 tubes glued side by side. The total thickness of the chamber, including adhesive and insulation material, was $7 \mathrm{~mm}$. The chambers for the rear of the calorimeter were built at ITEP according to a different design, sketched in fig. 5b. Each chamber plane consisted of nine "minichambers", each containing four sense wires alternating with potential wires and thus having four proportional cells with a lateral size of 12 


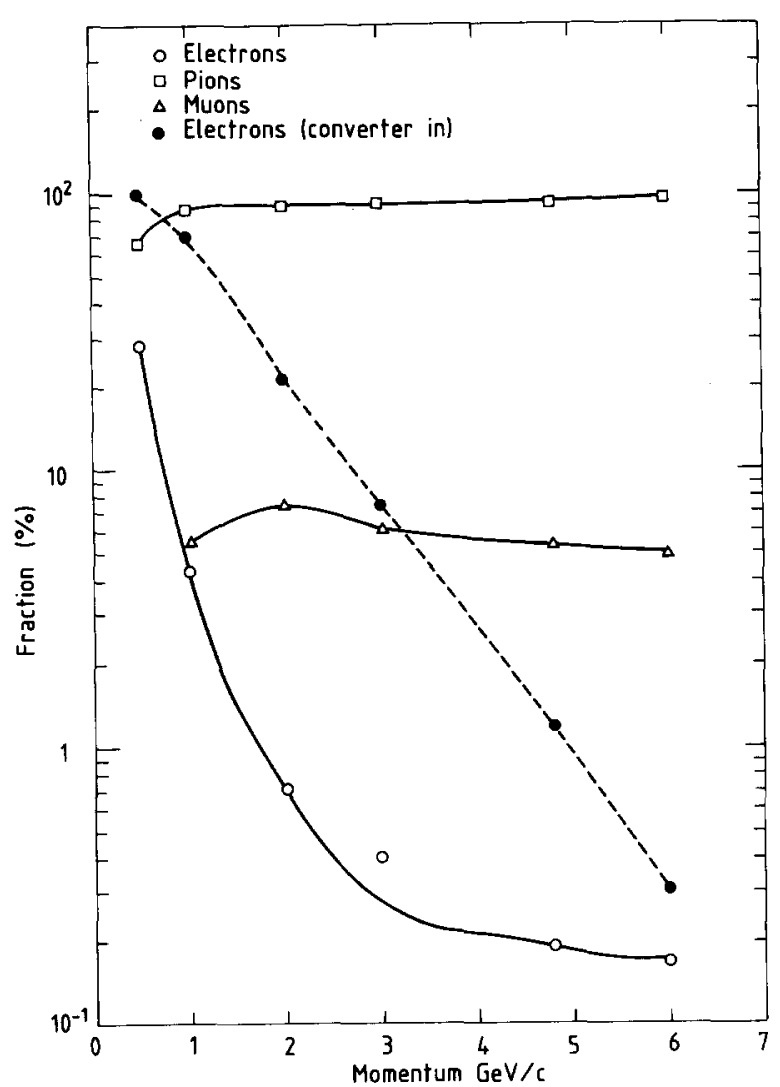

Fig. 1. The beam composition (ITEP test beam).

$\mathrm{mm}$. The chamber thickness in this case was $4.4 \mathrm{~mm}$. The number of chambers in the setup varied, but for most of the time there were 56 "Michigan" and 32 "ITEP" chambers.

The chambers were operated in the proportional mode with a relatively low gas gain of approximately $10^{4}$.

In this study several gas mixtures were used, with three different calorimeter structures which are listed in tables 1 and 2.

\section{Readout electronics}

Two types of readout electronics were used in this experiment: "slow" and "last". A detailed description of the slow electronics can be found in ref. [5]. As the circuit diagram of fig. 6 indicates, each channel starts with a charge-integrating amplifier with an $R C$ value of $0.5 \mu \mathrm{s}$, followed by a storage capacitor and multiplexed digitizer. The effective pulse width of the amplifier was approximately $2 \mu \mathrm{s}$; this relatively large width was responsible for the pileup effects due to uranium radio-

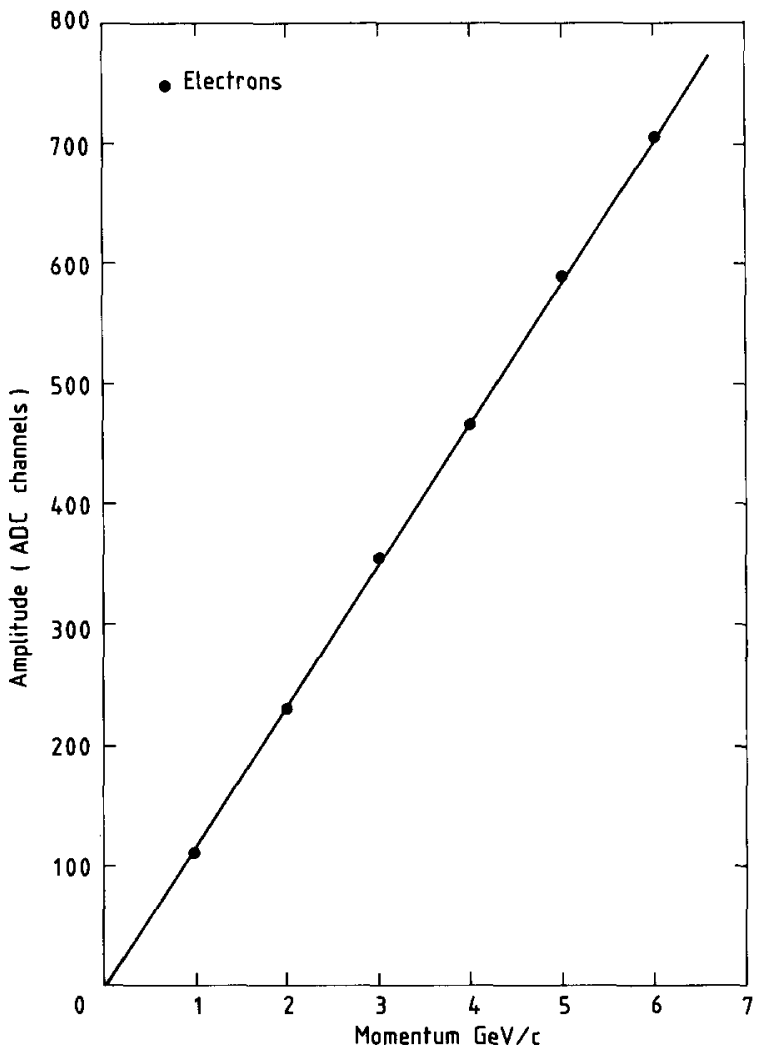

Fig. 2. The electron beam energy calibration with a lead-glass total absorption counter.

activity. Every five neighbouring wires of each chamber plane were combined into one electronics channel, resulting in rather fine granularity for the calorimeter. The linearity of the response of every channel was checked. Good linearity was observed down to very low levels, and no corrections for nonlinearity were necessary.

To ensure that our conclusions were not affected by the features of the slow electronics, some of the studies were carreid out using "fast" electronics. These consisted of current amplifiers followed by a commercial

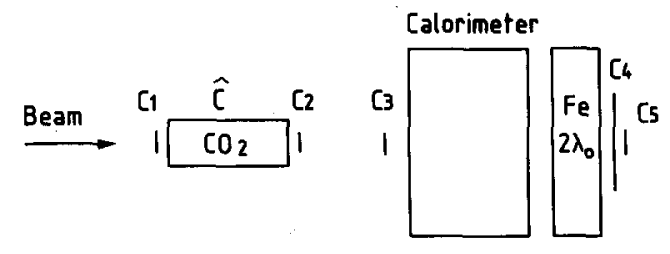

Mu-filter

Fig. 3. The ITEP experimental setup. 


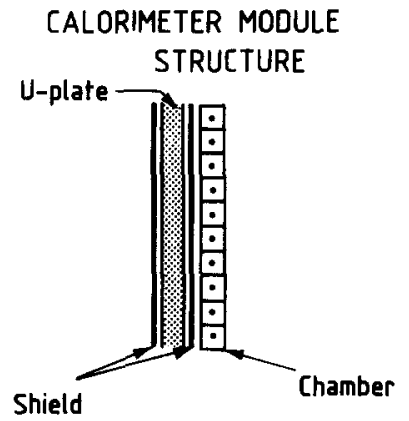

Fig. 4. The calorimeter module structure.

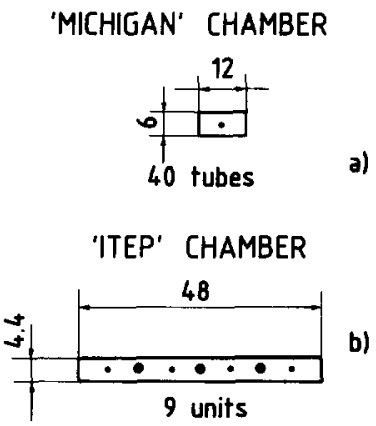

Fig. 5. The calorimeter proportional chamber construction, (a) "Michigan chamber", (b) "ITEP"chamber.

ADC unit, type LRS 2249A, as shown in the circuit diagram of fig. 7. The speed of a channel was defined by the ADC gate width, which was set to $300 \mathrm{~ns}$ in the present case. All 40 wires from an entire chamber plane were connected to one electronics channel. A linearity curve was measured for each channel, and the data were corrected for the observed nonlinearity in the least significant bits of the ADC.

Table 1

List of gas mixtures

\begin{tabular}{lc}
\hline Gas composition & Percentages \\
\hline (1) $\mathrm{Ar}+\mathrm{CO}_{2}$ & $80 / 20$ \\
(2) $\mathrm{Ar}+\mathrm{CO}_{2}$ & $12 / 88$ \\
(3) $\mathrm{Xe}+\mathrm{CO}_{2}$ & $80 / 20$ \\
(4) $\mathrm{iC}_{4} \mathrm{H}_{10}$ a) & 100 \\
(5) $\mathrm{Ar}+\mathrm{iC}_{4} \mathrm{H}_{10}$ & $42 / 58$ \\
(6) $\mathrm{Xe}+\mathrm{iC}_{4} \mathrm{H}_{10}$ & $88 / 12$ \\
(7) $\mathrm{CH}$ & 100 \\
(8) $\mathrm{Ar}+\mathrm{CH}_{4}$ & $50 / 50$ \\
\hline
\end{tabular}

a) Isobutane.
Table 2

List of calorimeter structures

\begin{tabular}{lll}
\hline Structure & $\begin{array}{l}\text { Total length } \\
\left(\lambda_{\text {abs }}\right)\end{array}$ & $\begin{array}{l}\text { Gas mixtures } \\
\text { (see table 1) }\end{array}$ \\
\hline $\begin{array}{l}\text { Uranium } 4.5 \mathrm{~mm}, \text { no shielding, } \\
88 \text { layers spaced by } 20 \mathrm{~mm}\end{array}$ & 3.8 & $1,4,5$ \\
$\begin{array}{l}\text { Uranium } 4.5 \mathrm{~mm} \text {, chambers are } \\
\text { shielded with } 1 \mathrm{~mm} \mathrm{Cu} \text { sheets, }\end{array}$ & \\
88 layers spaced by $18 \mathrm{~mm}$ & 5.0 & $1,4,5,6,7,8$ \\
$\begin{array}{l}43 \text { layers of } 9 \mathrm{~mm} \mathrm{U}, \\
10 \text { layers of } 4.5 \mathrm{~mm} \mathrm{U},\end{array}$ & \\
$\begin{array}{l}25 \text { layers of } 7 \mathrm{~mm} \mathrm{Cu} \text {, } \\
\text { spaced by } 20 \mathrm{~mm}, \text { no shielding }\end{array}$ & 5.3 & $1,2,3,4$ \\
\hline
\end{tabular}

\section{The calorimeter calibration}

The noise from the radioactivity of uranium provided an easy way of checking the uniformity of the calorimeter response, whereas the response to muons was used to make an absolute calibration.

Fig. 8 shows a typical spectrum obtained for the uranium noise in a single electronics channel. For amplitudes above $100 \mathrm{ADC}$ channels, the spectrum was fitted to an exponential dependence. The distribution of the fitted slope parameter in fig. 9 shows that the gain was uniform within $8 \%$ and no intercalibration corrections were necessary.

An example of a muon spectrum detected in one electronics channel is depicted in fig. 10. These spectra were fitted by a Landau-like function:

$\mathrm{d} N / \mathrm{d} Q=A \mathrm{e}^{-\left(Q+\mathrm{e}^{-\ell}\right) / 2}$,

where $Q=\left(A-A^{\prime}\right) / G$, with $A$ the amplitude in ADC channels, and $A^{\prime}$ the most probable amplitude.

The distribution of the parameter $G$, which corresponds to the gain of a given channel, is shown in fig. 11. It demonstrates that the gain uniformity is within $10 \%$ and is in agreement with the value obtained from the uranium noise.

The absolute calibration was made by measuring the total response of the calorimeter to muons. A typical distribution of this response can be seen in fig. 12. In fig. 13 the mean muon response is plotted as a function of the muon energy for two of the gas mixtures used. Similar plots were obtained for all gas mixtures and the data were used to evaluate the "mip", i.e. the response of a single chamber plane to a minimum-ionizing particle. The measured values of mip at different energies were found to be in agreement with Monte Carlo predictions. Throughout this paper the calorimeter response will be expressed in mip, which is defined as the 


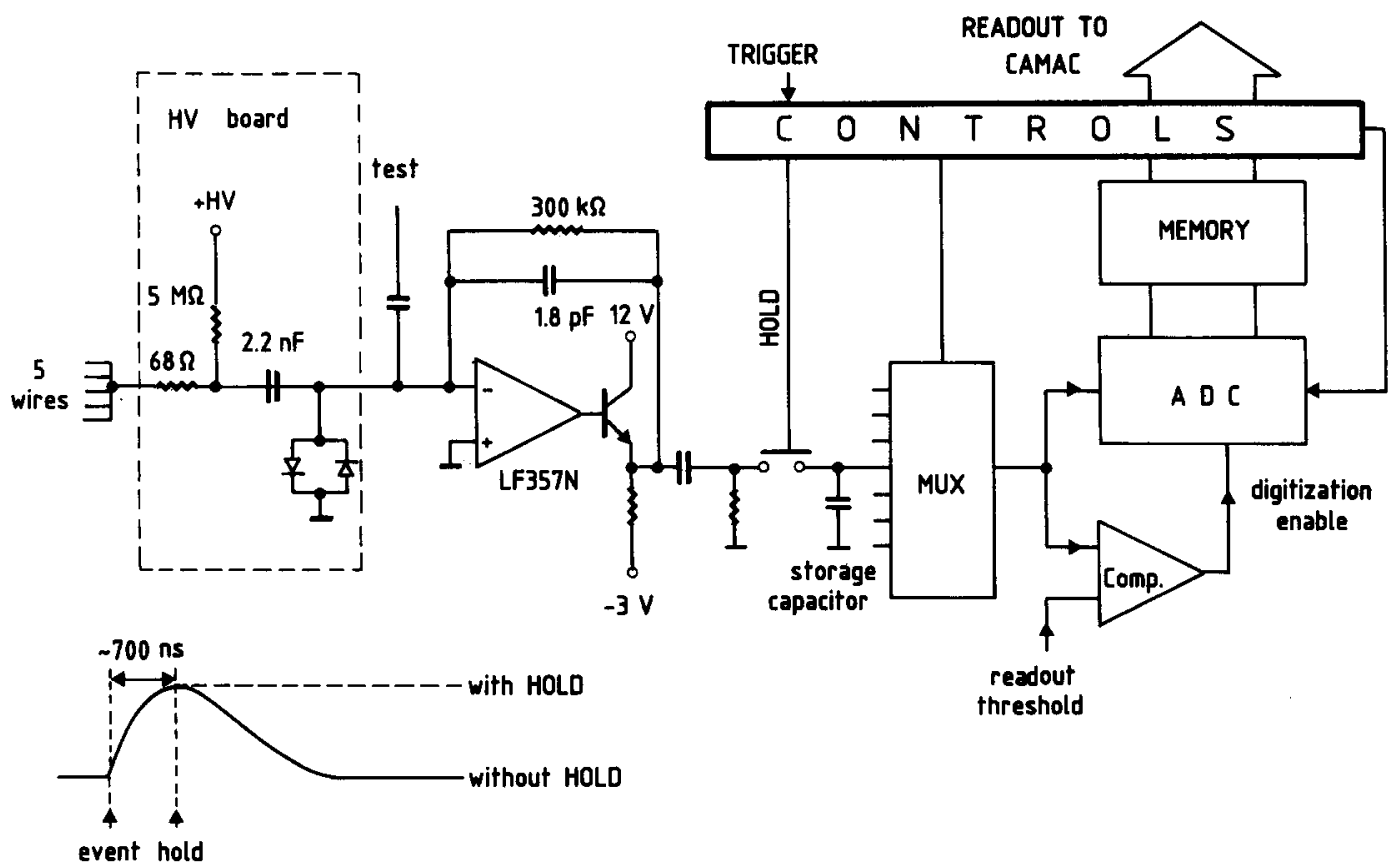

Voltage on storage capacitor

Fig. 6. Circuit diagram of the "slow" electronics.

response of the calorimeter to muons of $2 \mathrm{GeV}$ energy and is obtained by passing a smooth curve through the data points as illustrated in fig. 13. The values of mip are given in table 3.

\section{Pion, electron, and muon separation}

Muons were selected by the coincidence of counters C1-C5 shown in fig. 3. The measured admixture of punchthrough pions in the trigger was below 1\%
The electron trigger consisted of the threshold Cherenkov counter in coincidence with the counters $\mathrm{Cl}-\mathrm{C} 3$, which gave a pure electron sample up to $4 \mathrm{GeV}$. However, above $4 \mathrm{GeV}$, where the fraction of electrons in the beam was too low, a software cut was applied which was based on the shower density (number of hits) in the vicinity of the electron shower maximum. Finally, $96 \%$ of the pions, $99.8 \%$ of the muons, and only $0.2 \%$ of the electrons were rejected. As an example, separation of electrons from pions and muons is shown in fig. 14, where the position of the cut is also indicated.

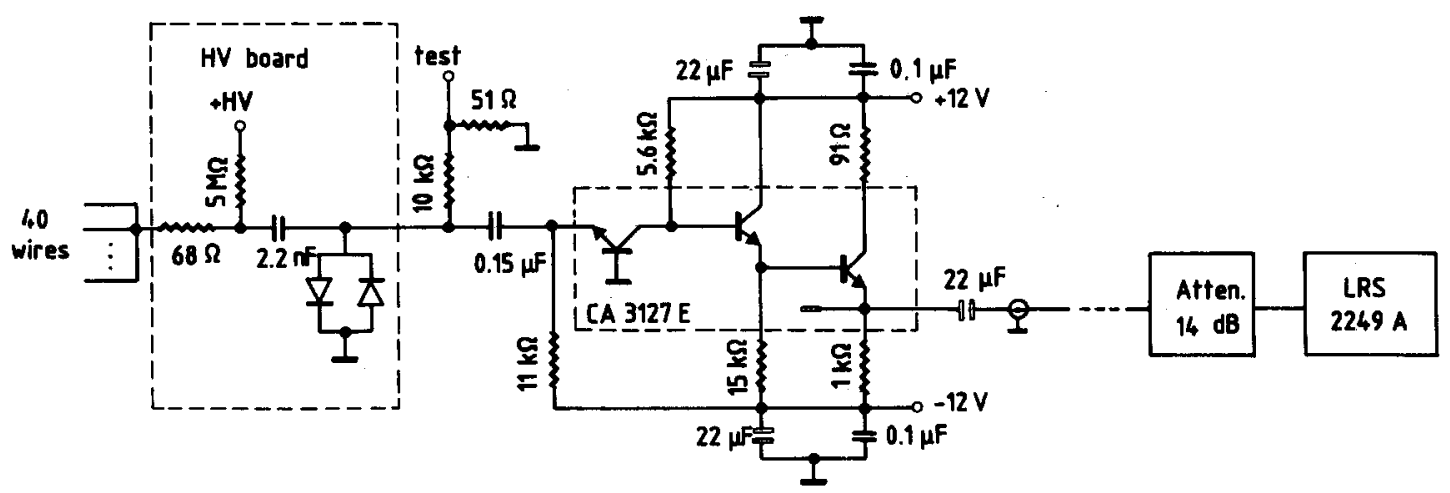

Fig. 7. Circuit diagram of the "fast" electronics. 


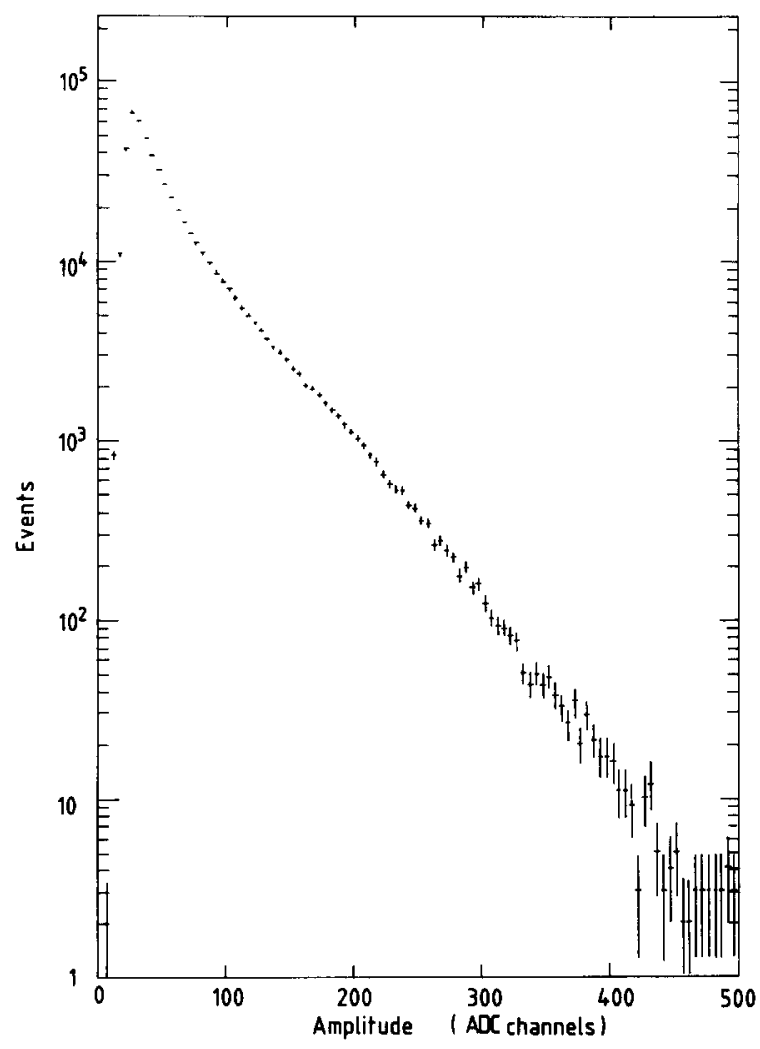

Fig. 8. The spectrum of uranium noise for one electronics channel taken with random trigger for "Michigan" chambers filled with $\mathrm{Xe}(80 \%)+\mathrm{CO}_{2}(20 \%)$

The pion trigger $-\mathrm{C} 1-\mathrm{C} 3$ in coincidence and Cherenkov + C4 in anticoincidence - was sufficient to reduce the muon contamination down to the less than $1 \%$ level at energies above $2 \mathrm{GeV}$, as illustrated in fig. 15. However, a $1 \mathrm{GeV}$ muon stopped inside the calorimeter, never reaching the veto counter $\mathrm{C} 4$. Therefore for 1 $\mathrm{GeV}$ data the following software procedure was adopted

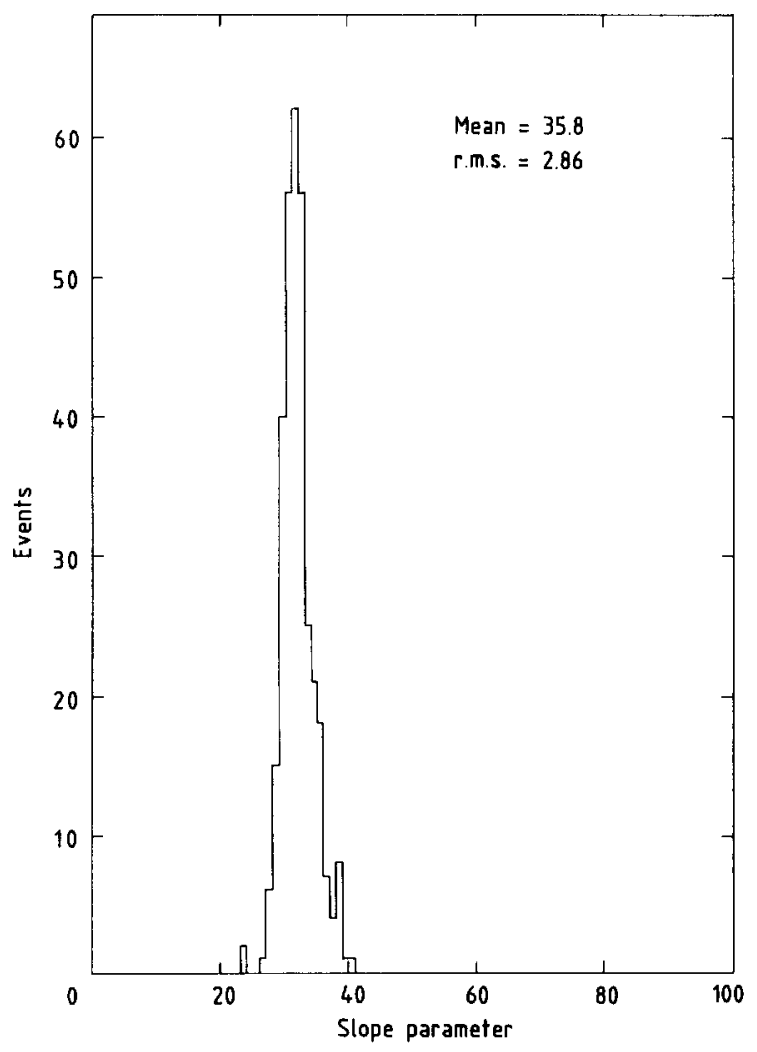

Fig. 9. Gain uniformity check with uranium noise. The distribution of the slope parameter of the uranium noise spectrum is shown. The parameter is inversely proportional to the channel gain.

in order to reduce the muon contamination.

First the distribution of the response of each chamber plane to a pure sample of $2 \mathrm{GeV}$ muons was used to establish a muon reference line for that chamber. For chambers beyond the range of a $1 \mathrm{GeV}$ muon the reference line was set to zero. Then each shower was compared with these reference lines on a plane-by-plane

Table 3

Mean response to $2 \mathrm{GeV} / c$ muons (ADC channels); "slow" ("fast") electronics

\begin{tabular}{|c|c|c|c|c|c|}
\hline \multirow[t]{2}{*}{ Gas [\%] } & \multicolumn{5}{|l|}{ Structure } \\
\hline & $\begin{array}{l}4.5 \mathrm{~mm} \mathrm{U} \\
1.0 \mathrm{~mm} \mathrm{Cu}\end{array}$ & & $\begin{array}{l}4.5 \mathrm{~mm} \mathrm{U} \\
\text { no shielding }\end{array}$ & & $\begin{array}{l}9.0 \mathrm{~mm} \\
\text { no shielding }\end{array}$ \\
\hline $\mathrm{Ar}+\mathrm{CO}_{2}, 80 / 20$ & $15.0 \pm 0.75$ & $(6.0 \pm 0.48)$ & $15.5 \pm 0.93$ & & $13.2 \pm 0.53$ \\
\hline $\mathrm{Ar}+\mathrm{CO}_{2}, 12 / 88$ & & & & & $10.6 \pm 0.64$ \\
\hline $\mathrm{Xe}+\mathrm{CO}_{2}, 80 / 20$ & & & & & $11.5 \pm 0.46$ \\
\hline $\mathrm{Xe}+\mathrm{iC}_{4} \mathrm{H}_{10}, 82 / 18$ & & $(5.6 \pm 0.50)$ & & & \\
\hline $\mathrm{Ar}+\mathrm{CH}_{4}, 50 / 50$ & $12.3 \pm 0.49$ & & & & \\
\hline $\mathrm{CH}_{4}, 100$ & $11.3 \pm 0.57$ & & & & \\
\hline $\mathrm{Ar}+\mathrm{iC}_{4} \mathrm{H}_{10}, 42 / 58$ & $25.5 \pm 1.28$ & & $18.9 \pm 1.13$ & & \\
\hline $\mathrm{iC}_{4} \mathrm{H}_{10}, 100$ & $8.7 \pm 0.35$ & $(5.38 \pm 0.43)$ & $17.0 \pm 1.70$ & $(6.0 \pm 0.48)$ & $17.0 \pm 0.85$ \\
\hline
\end{tabular}




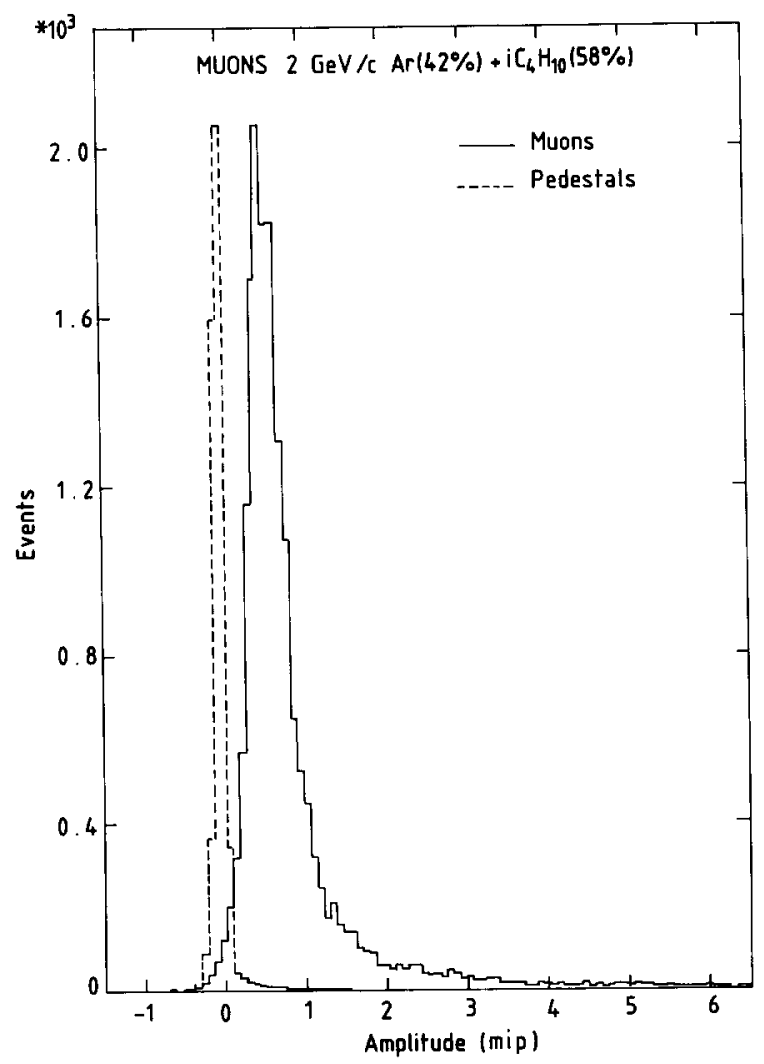

Fig. 10. The response to muons for one electronics channel.

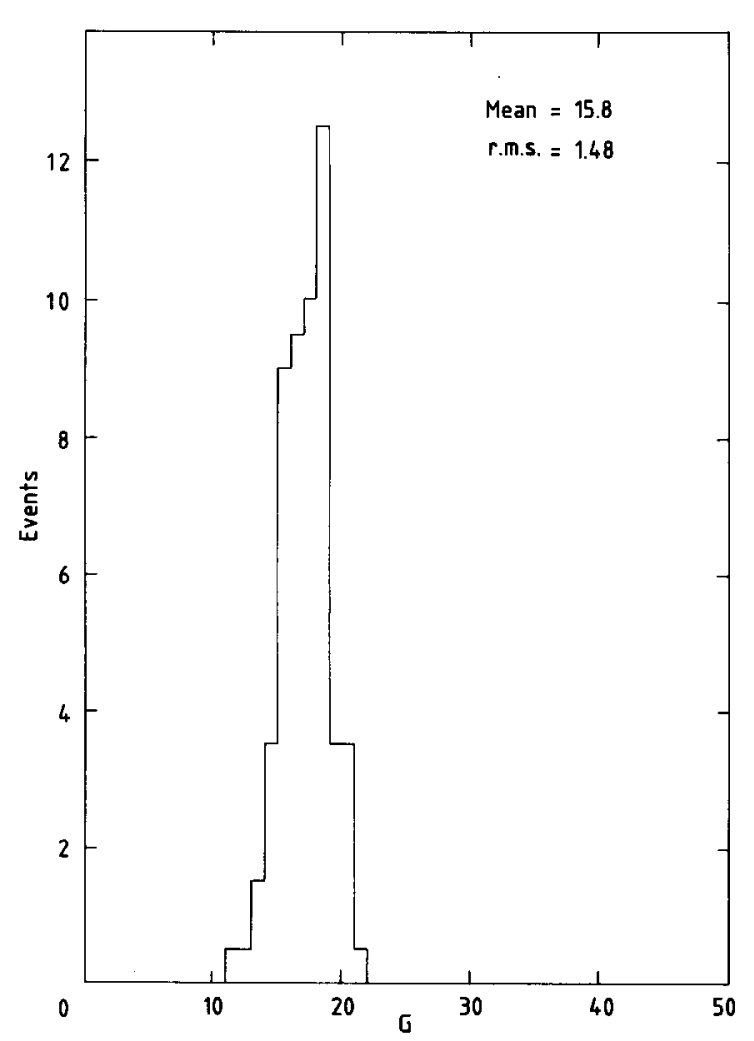

Fig. 11. Gain uniformity check with muons. The distribution of the parameter $G$ extracted from the muon spectrum is shown (see text).

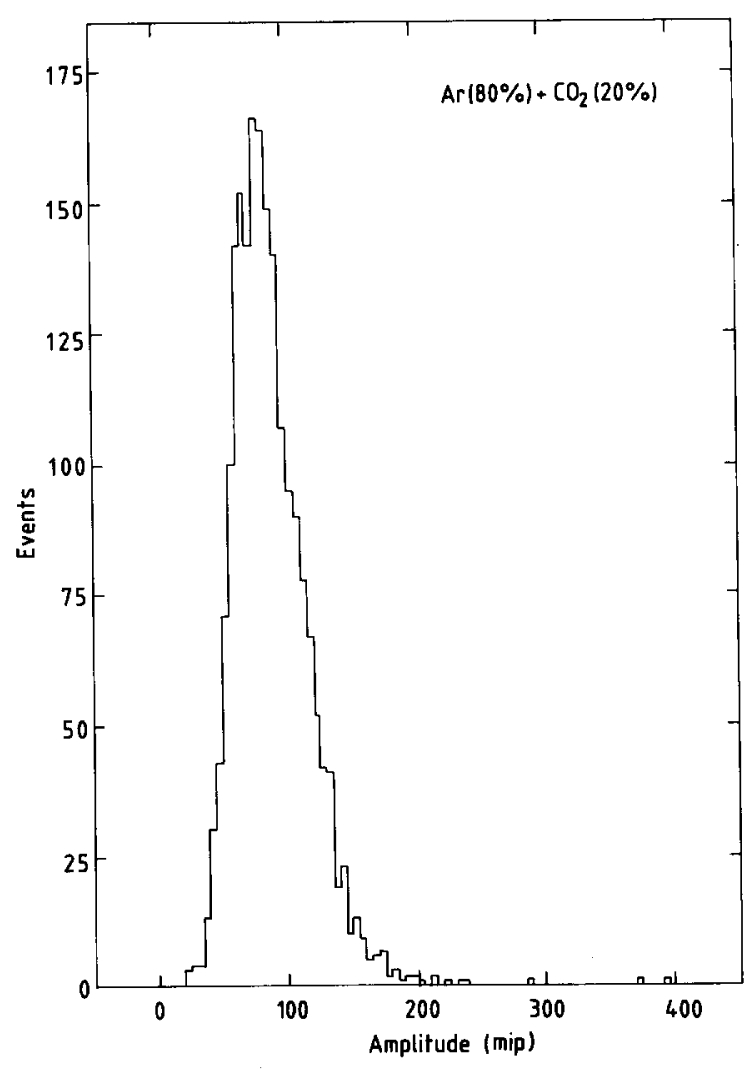

Fig. 12. The calorimeter response to $2 \mathrm{GeV}$ muons.

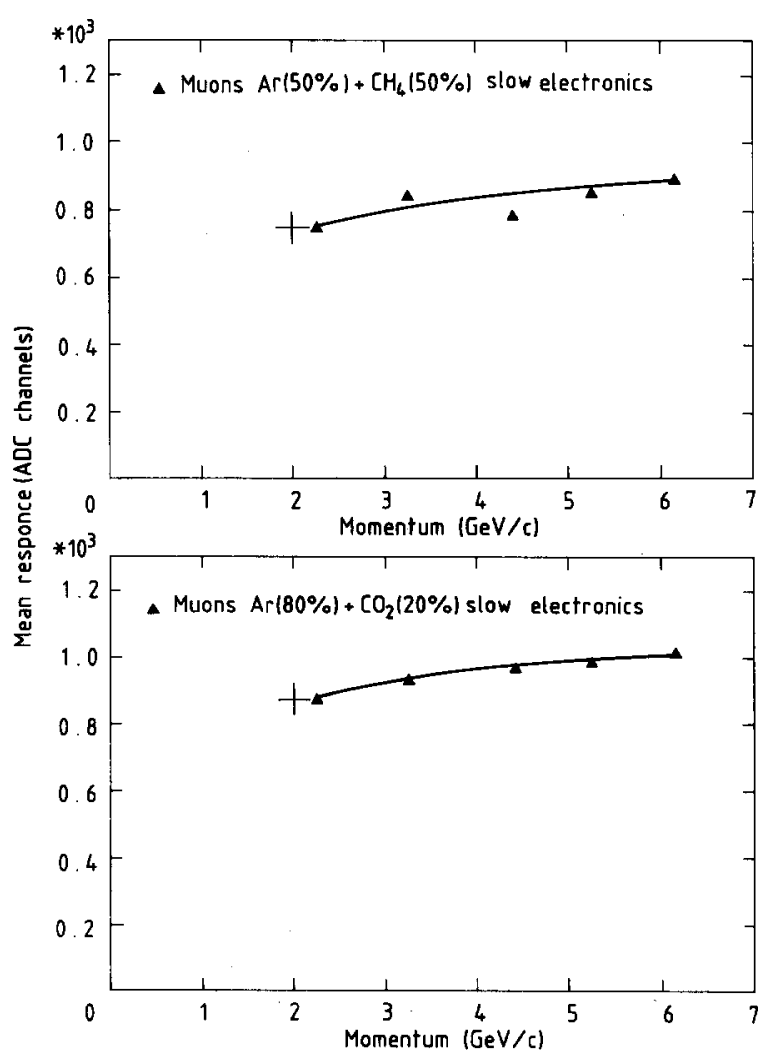

Fig. 13. The mean calorimeter response to muons vs muon momentum. The value used for mip definition is marked $(t)$. The structure is $4.5 \mathrm{~mm}$ uranium $+1 \mathrm{~mm}$ copper shielding. 


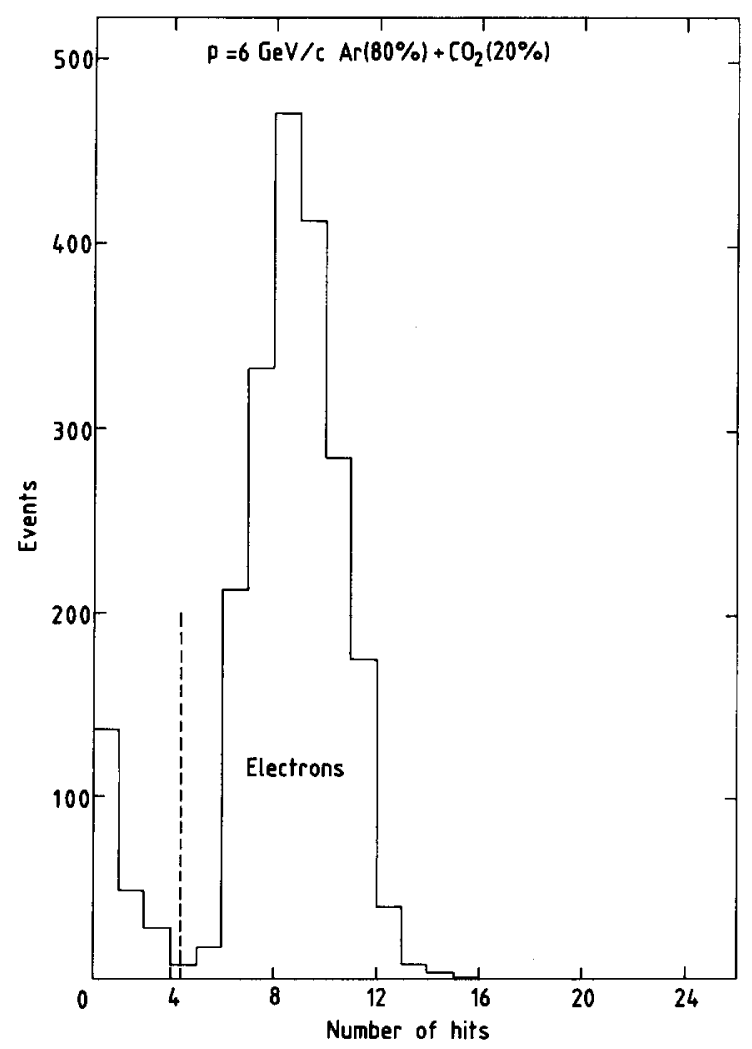

Fig. 14. Separation of electrons from pions. The applied cut in software is indicated. The horizontal axis reflects the shower density (see text).

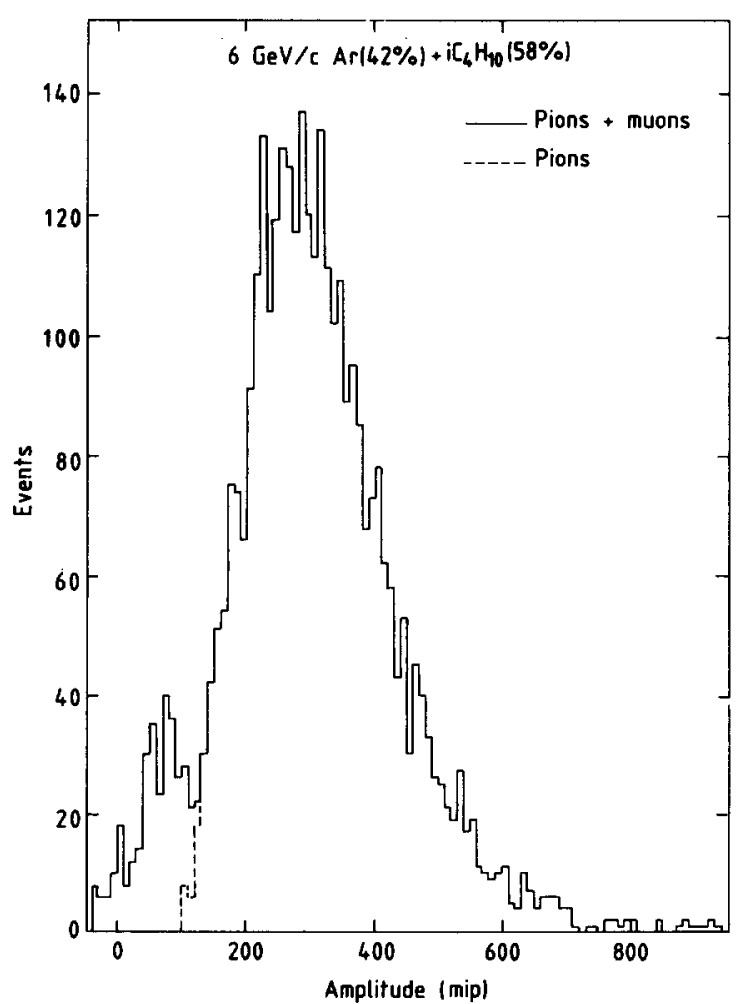

Fig. 15. The muon separation from pions at $6 \mathrm{GeV}$ by muon trigger counter.

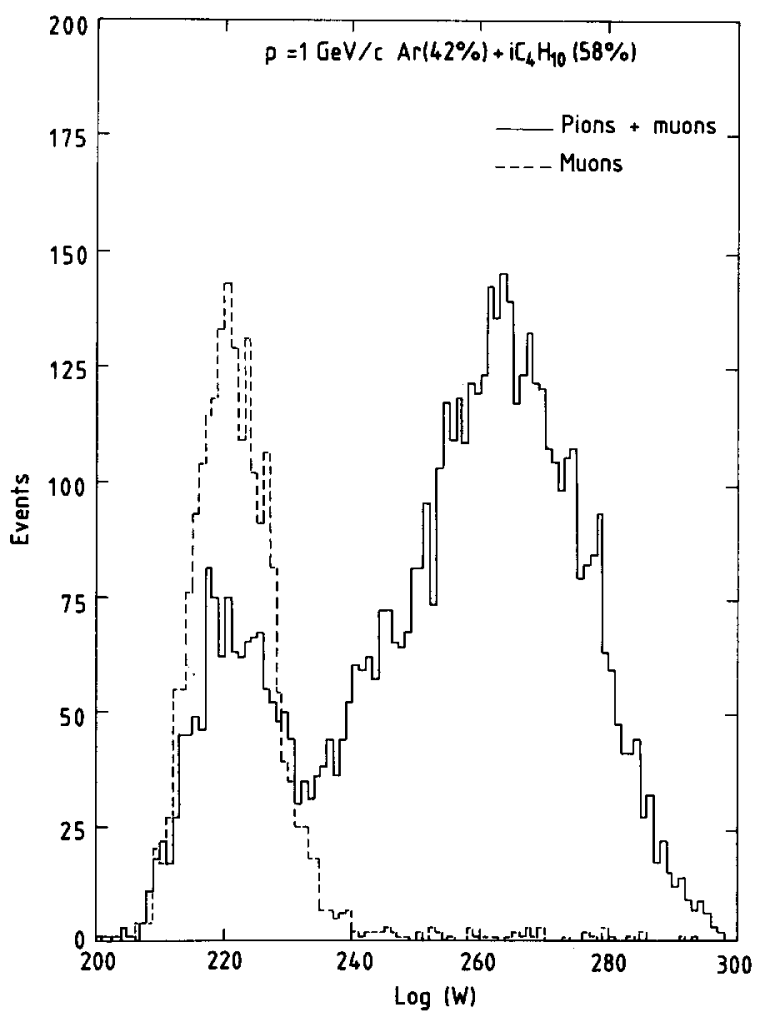

Fig. 16. The muon separation from pions by software at $1 \mathrm{GeV}$ (see text). On the abscissa, $W$ is the value of the likelihood function.

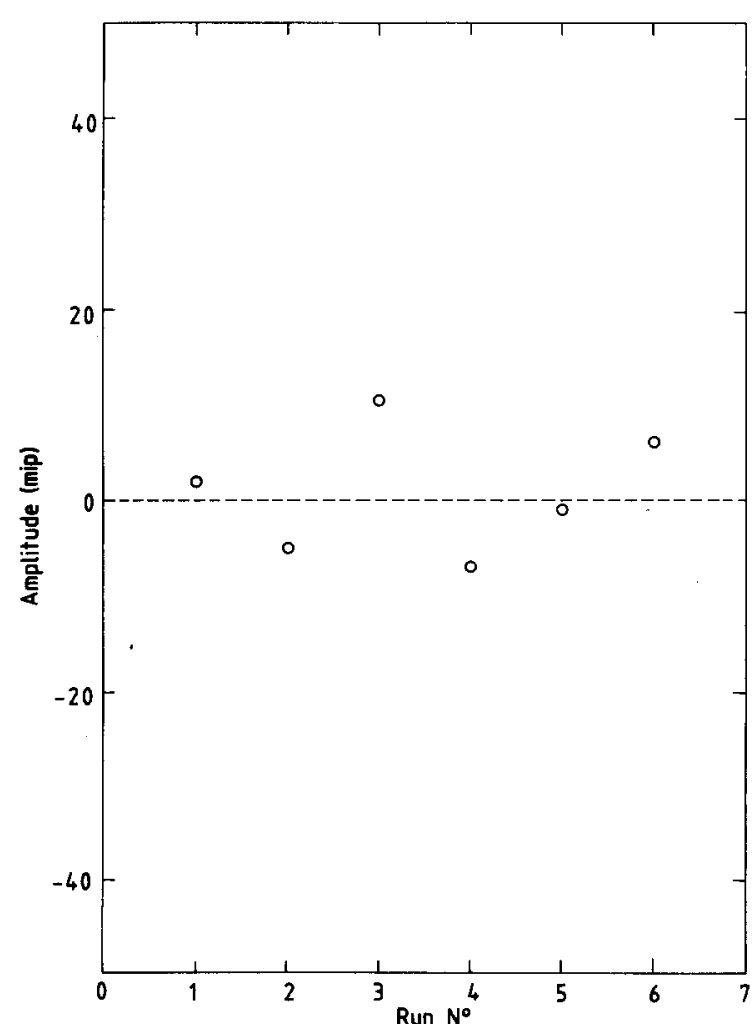

Fig. 17. The pedestal value measured in different runs with slow electronics and an $\mathrm{Ar} / \mathrm{CO}_{2}$ gas mixture. The structure is $4.5 \mathrm{~mm} \mathrm{U}+1 \mathrm{~mm} \mathrm{Cu}$ shielding. The systematic error estimated from the drift is approximately $7 \mathrm{mip}$. 
basis, and the corresponding value of a likelihood function was calculated. The result can be seen in fig. 16, where the distribution for the muons is also shown.

Another procedure which was used at $1 \mathrm{GeV}$ was to estimate the muon signal from the knowledge of the muon response and the beam composition as given in fig. 1 , and to subtract it from the distribution of the calorimeter response.

We estimate that after the rejection the muon contamination is below $2 \%$, and less than $2 \%$ of pions are rejected.

\section{Error analysis summary}

Before presenting the results, a short summary of the error analysis is given.

The statistical errors were negligible and all uncertainties were due to systematics. The following sources of systematic errors were identified:

1) Pedestal instability: An example of pedestal drift is shown in fig. 17. The error due to this instability in the presence of uranium noise is estimated to be rms $<7 \mathrm{mip}$.

2) The scale of the calorimeter response is determined by the muon calibration with an uncertainty of $\mathrm{d} E / E=5 \%$.

3) The uncertainty in corrections for the nonlinearity of the ADCs in the "fast" electronics gives

$\mathrm{d} E / E=7 \%$.

\section{Results}

As an example, the response of the calorimeter to 6 $\mathrm{GeV}$ pions and electrons is presented in fig. 18 for two different gases. The mean values of the calorimeter response at different energies and for different gas mixtures are summarized in tables 4 and 5 . The errors are given in the last two columns; $e_{1}$ is in units of mip and $e_{2}$ in percent. (They should be combined in quadrature.)

In fig. 19 the mean response of the calorimeter is plotted as a function of incident energy for the above two gases. It demonstrates the linearity of the calorimeter response for both pions and electrons in the energy range studied. The slopes for electrons in the two gases are the same within normalization errors, whereas the slopes for pions are quite different. The values of the slope (i.e. the calorimeter response per $\mathrm{GeV}$ expressed in mip), are listed for all calorimeter configurations and gases in tables 6 and 7. The corresponding ratios of the pion to electron responses are given in table 8.

The mean responses per $\mathrm{GeV}$ plotted against the
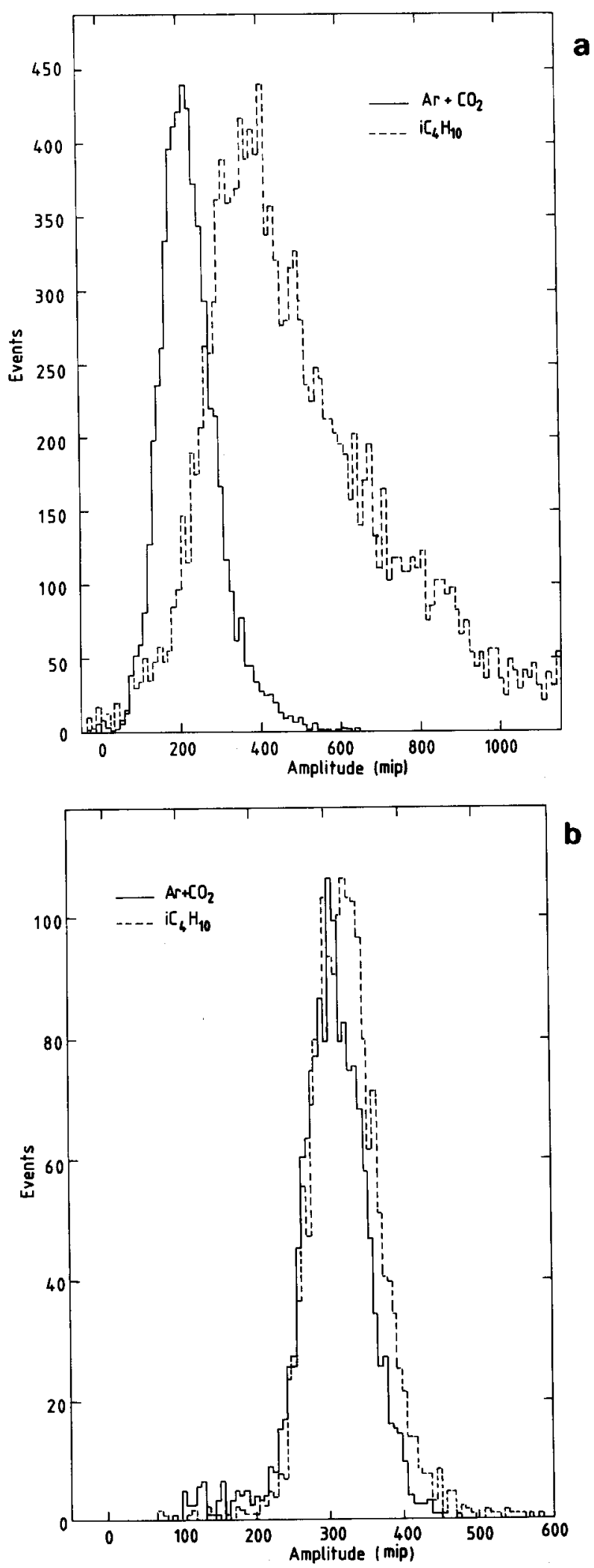

Fig. 18. The calorimeter response for $\operatorname{Ar}(80 \%)+\mathrm{CO}_{2}(20 \%)$ and pure isobutane to (a) $6 \mathrm{GeV}$ pions, (b) $6 \mathrm{GeV}$ electrons. 
relative hydrogen density (fig. 20) confirms that no gas dependence of the response is observed for electrons. On the contrary, for pions the average amplitude per $\mathrm{GeV}$ increases with the increasing hydrogen content of the gas.

In order to check this observation the measurements were repeated with modifications introduced in the apparatus.

First the measurement with the "fast" electronics was made. Then the $1 \mathrm{~mm}$ copper shielding was removed and the measurement was repeated. The results are shown in figs. 21 and 22, and the observations are essentially the same, namely: for electrons no gas de- pendence is observed, but for pions the dependence is well pronounced.

Finally, the calorimeter structure was changed: a second $4.5 \mathrm{~mm}$ uranium plate was put in front of every chamber, thus increasing the average calorimeter density. As shown in fig. 23, the gas dependence for pions becomes even stronger, whereas for electrons yet again no dependence is seen. From fig. 23 one can make another important observation: if a gas mixture does not contain hydrogen, neither electrons nor pions show any noticeable gas dependence.

The observed gas dependence of the pion response can be illustrated by the longitudinal development of

Table 4

Calorimeter response to electrons (mip)

(a) $4.5 \mathrm{~mm} \mathrm{U}+1.0 \mathrm{~mm}$ Cu shielding; "slow" electronics

\begin{tabular}{lllllllll}
\hline Gas [\%] & \multicolumn{2}{l}{ Energy [GeV] } \\
\cline { 2 - 9 } & 1.10 & 2.25 & 3.35 & 4.40 & 5.25 & 6.15 & $e_{1}[\mathrm{mip}]$ & $e_{2}[\%]$ \\
\hline $\mathrm{Ar}+\mathrm{CO}_{2}, 80 / 20$ & 60 & 122 & 183 & 238 & 280 & 326 & 7 & 5 \\
$\mathrm{Ar}+\mathrm{CH}_{4}, 50 / 50$ & 57 & 118 & 175 & 232 & 273 & & 7 & 4 \\
$\mathrm{CH}_{4}, 100$ & 60 & 121 & 177 & 232 & 272 & 315 & 5 & 4 \\
$\mathrm{Ar}+\mathrm{iC}_{4} \mathrm{H}_{10}, 42 / 58$ & 57 & 119 & 181 & 240 & 284 & & 5 & 5 \\
$\mathrm{iC}_{4} \mathrm{H}_{10}, 100$ & 62 & 128 & 197 & 260 & 305 & 352 & 7 & 4
\end{tabular}

(b) $4.5 \mathrm{~mm} \mathrm{U}+1.0 \mathrm{~mm} \mathrm{Cu}$ shielding; "fast" electronics

\begin{tabular}{lllllllll}
\hline Gas [\%] & \multicolumn{2}{l}{ Energy [GeV] } & \multicolumn{1}{l}{} & \\
\cline { 2 - 9 } & 1.08 & 2.15 & 3.25 & 4.30 & 5.22 & 6.20 & $e_{1}[\mathrm{mip}]$ & $e_{2}[\%]$ \\
\hline $\mathrm{Ar}+\mathrm{CO}_{2}, 80 / 20$ & 56 & 115 & 175 & 228 & 275 & 325 & 7 & 8 \\
$\mathrm{Xe}+\mathrm{iC}_{4} \mathrm{H}_{10}, 82 / 18$ & 67 & 132 & 190 & 236 & 305 & 345 & 7 & 9 \\
$\mathrm{iC}_{4} \mathrm{H}_{10}, 100$ & 53 & 114 & 172 & 227 & 261 & 316 & 7 & 8
\end{tabular}

(c) $4.5 \mathrm{~mm} \mathrm{U}+$ no shielding; "slow" electronics

\begin{tabular}{|c|c|c|c|c|c|c|c|c|}
\hline \multirow[t]{2}{*}{ Gas [\%] } & \multicolumn{8}{|c|}{ Energy $[\mathrm{GeV}]$} \\
\hline & 1 & 2 & 3 & 4 & 5 & 6 & $e_{1}$ [mip] & $\overline{e_{2}[\mathscr{6}]}$ \\
\hline $\mathrm{Ar}+\mathrm{CO}_{2}, 80 / 20$ & & 144 & & 303 & & 445 & 7 & 6 \\
\hline $\mathrm{Ar}+\mathrm{iC}_{4} \mathrm{H}_{10}, 50 / 50$ & & 148 & & 287 & & 421 & 7 & 6 \\
\hline $\mathrm{iC}_{4} \mathrm{H}_{10}, 100$ & & & & & & 488 & 7 & 10 \\
\hline
\end{tabular}

(d) $4.5 \mathrm{~mm} \mathrm{U}+$ no shielding; "fast" electronics

\begin{tabular}{|c|c|c|c|c|c|c|c|c|}
\hline \multirow[t]{2}{*}{ Gas [\%] } & \multicolumn{8}{|c|}{ Energy [GeV] } \\
\hline & 1.08 & 2.15 & 3.25 & 4.30 & 5.22 & 6.20 & $e_{1}$ [mip] & $e_{2}[\%]$ \\
\hline $\mathrm{iC}_{4} \mathrm{H}_{10}, 100$ & 78 & 154 & 240 & 315 & 377 & 437 & 7 & 8 \\
\hline
\end{tabular}

(e) $9.0 \mathrm{~mm} \mathrm{U}+$ no shielding; "slow" electronics

\begin{tabular}{lllllllll}
\hline Gas [\%] & \multicolumn{1}{l}{ Energy [GeV] } & & & & & \\
\cline { 2 - 9 } & 1 & 2 & 3 & 4 & 5 & 6 & $e_{1}[\mathrm{mip}]$ & $e_{2}[\%]$ \\
\hline $\mathrm{Ar}+\mathrm{CO}_{2}, 80 / 20$ & 35 & 69 & 104 & 141 & 176 & 208 & 4 & 3 \\
$\mathrm{Ar}+\mathrm{CO}_{2}, 12 / 88$ & 38 & 79 & 112 & 152 & 186 & 221 & 3 & 6 \\
$\mathrm{Xe} / \mathrm{CO}_{2}, 80 / 20$ & & 70 & & 143 & & 210 & 3 & 3 \\
$\mathrm{iC} \mathrm{H}_{10}, 100$ & & 72 & & 153 & & 220 & 4 & 4 \\
\hline
\end{tabular}


Table 5

Calorimeter response to pions (mip)

(a) $4.5 \mathrm{~mm} \mathrm{U}+1.0 \mathrm{~mm}$ Cu shielding; "slow" electronics

\begin{tabular}{lrrllllll}
\hline Gas [\%] & \multicolumn{2}{l}{ Energy [GeV] } & & & & \\
\cline { 2 - 9 } & 1.10 & 2.25 & 3.35 & 4.40 & 5.25 & 6.15 & $e_{1}[\mathrm{mip}]$ & $e_{2}[\%]$ \\
\hline $\mathrm{Ar}+\mathrm{CO}_{2}, 80 / 20$ & 49 & 82 & 138 & 187 & 227 & 260 & 7 & 4 \\
$\mathrm{Ar}+\mathrm{CH}_{4}, 50 / 50$ & 54 & 109 & 167 & 210 & 253 & 300 & 7 & 4 \\
$\mathrm{CH}_{4}, 100$ & 70 & 150 & 214 & 284 & 326 & 387 & 5 & 4 \\
$\mathrm{Ar}+\mathrm{iC}_{4} \mathrm{H}_{10}, 42 / 58$ & 68 & 132 & 205 & 269 & 320 & & 5 & 5 \\
$\mathrm{iC}_{4} \mathrm{H}_{10}, 100$ & 102 & 190 & 275 & 378 & 435 & 503 & 7 & 4
\end{tabular}

(b) $4.5 \mathrm{~mm} \mathrm{U}+1.0 \mathrm{~mm} \mathrm{Cu}$ shielding; "fast" electroncis

\begin{tabular}{lccccccccc}
\hline Gas [\%] & \multicolumn{1}{l}{ Energy [GeV] } & \multicolumn{1}{l}{} & \\
\cline { 2 - 9 } & 1.08 & 2.15 & 3.25 & 4.30 & 5.22 & 6.20 & $e_{1}[\mathrm{mip}]$ & $e_{2}[\%]$ \\
\hline $\mathrm{Ar}+\mathrm{CO}_{2}, 80 / 20$ & 54 & 72 & 126 & 175 & 220 & 256 & 7 & 8 \\
$\mathrm{Xe}+\mathrm{iC}_{4} \mathrm{H}_{10}, 82 / 18$ & 50 & 94 & 145 & 190 & 233 & 278 & 7 & 9 \\
$\mathrm{iC}_{4} \mathrm{H}_{10}, 100$ & 76 & 152 & 230 & 306 & 374 & 434 & 7 & 8
\end{tabular}

(c) 4.5 mm U + no shielding; "slow" electronics

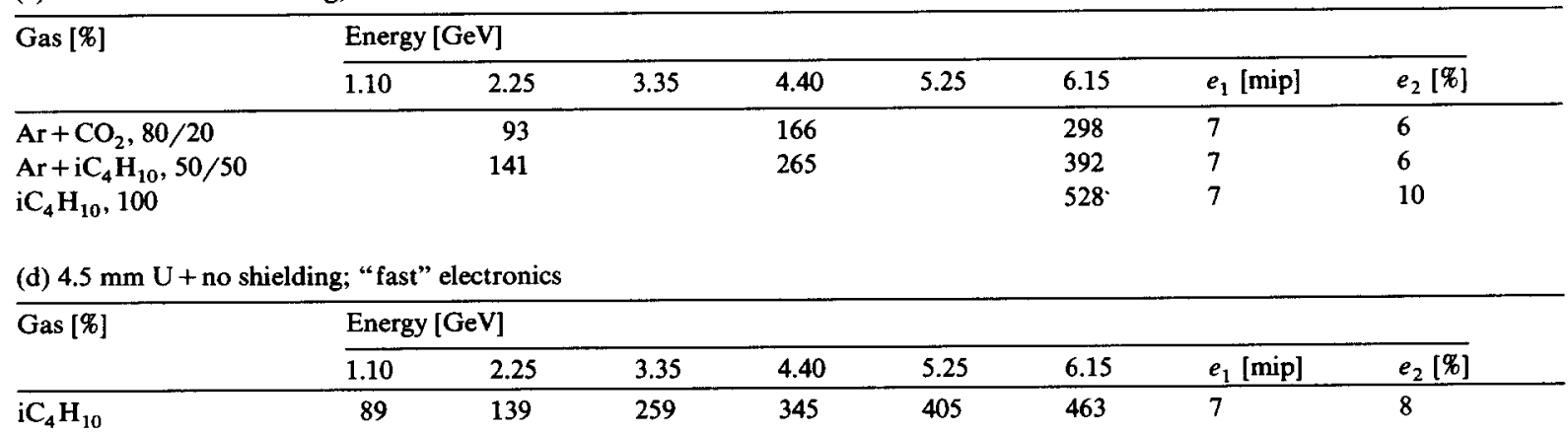

(e) $9.0 \mathrm{~mm} \mathrm{U}+$ no shielding; "slow" electronics

\begin{tabular}{lllllllll}
\hline Gas [\%] & \multicolumn{2}{l}{ Energy [GeV] } & & & & \\
\cline { 2 - 8 } & 1 & 2 & 3 & 4 & 5 & 6 & $e_{1}[\mathrm{mip}]$ & $e_{2}[\%]$ \\
\hline $\mathrm{Ar}+\mathrm{CO}_{2}, 80 / 20$ & 35 & 60 & 90 & 118 & 147 & 172 & 5 & 4 \\
$\mathrm{Ar}+\mathrm{CO}_{2}, 12 / 88$ & 32 & 62 & 95 & 125 & 164 & 195 & 4 & 6 \\
$\mathrm{Xe} / \mathrm{CO}_{2}, 80 / 20$ & & 57 & & 111 & & 166 & 4 & 4 \\
$\mathrm{iC}_{4} \mathrm{H}_{10}, 100$ & & 160 & & 313 & & 475 & 5 & 4 \\
\hline
\end{tabular}

Table 6

Mean response to electrons (mip/GeV); "slow" ("fast") electronics

\begin{tabular}{|c|c|c|c|c|c|}
\hline \multirow[t]{2}{*}{ Gas [\%] } & \multicolumn{5}{|l|}{ Structure } \\
\hline & $\begin{array}{l}4.5 \mathrm{~mm} \mathrm{U} \\
1.0 \mathrm{~mm} \mathrm{Cu}\end{array}$ & & $\begin{array}{l}4.5 \mathrm{~mm} \mathrm{U} \\
\text { no shielding }\end{array}$ & & $\begin{array}{l}9.0 \mathrm{~mm} \\
\text { no shielding }\end{array}$ \\
\hline $\mathrm{Ar}+\mathrm{CO}_{2}, 80 / 20$ & $54.0 \pm 2.7$ & $(52.8 \pm 4.2)$ & $74.2 \pm 4.4$ & & $35.0 \pm 1.4$ \\
\hline $\mathrm{Ar}+\mathrm{CO}_{2}, 12 / 88$ & & & & & $37.3 \pm 2.2$ \\
\hline $\mathrm{Xe}+\mathrm{CO}_{2}, 80 / 20$ & & & & & $34.8 \pm 1.4$ \\
\hline $\mathrm{Xe}+\mathrm{iC}_{4} \mathrm{H}_{10}, 82 / 18$ & & $(57.3 \pm 4.9)$ & & & \\
\hline $\mathrm{Ar}+\mathrm{CH}_{4}, 50 / 50$ & $52.5 \pm 2.1$ & & & & \\
\hline $\mathrm{CH}_{4}, 100$ & $51.7 \pm 2.1$ & & & & \\
\hline $\mathrm{Ar}+\mathrm{iC}_{4} \mathrm{H}_{10}, 42 / 58$ & $54.5 \pm 2.8$ & & $71.5 \pm 4.3$ & & \\
\hline $\mathrm{iC}_{4} \mathrm{H}_{10}, 100$ & $57.8 \pm 2.3$ & $(51.6 \pm 4.1)$ & $80.5 \pm 8.1$ & $(72.5 \pm 7.4)$ & $37.7 \pm 1.8$ \\
\hline
\end{tabular}




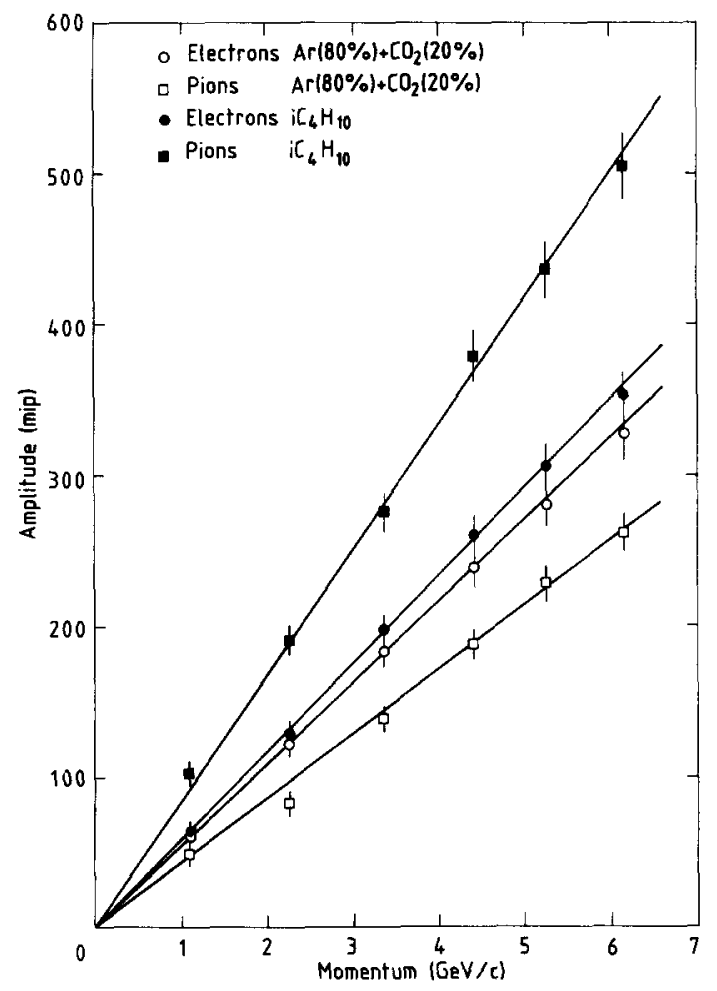

Fig. 19. The calorimeter response to pions and electrons vs incident energy. The size of the dots reflects the point-to-point error of the data, whereas the bars correspond to the normalization uncertainty. The structure is $4.5 \mathrm{~mm} \mathrm{U}+1 \mathrm{~mm} \mathrm{Cu}$ shielding. Data are taken with slow electronics.
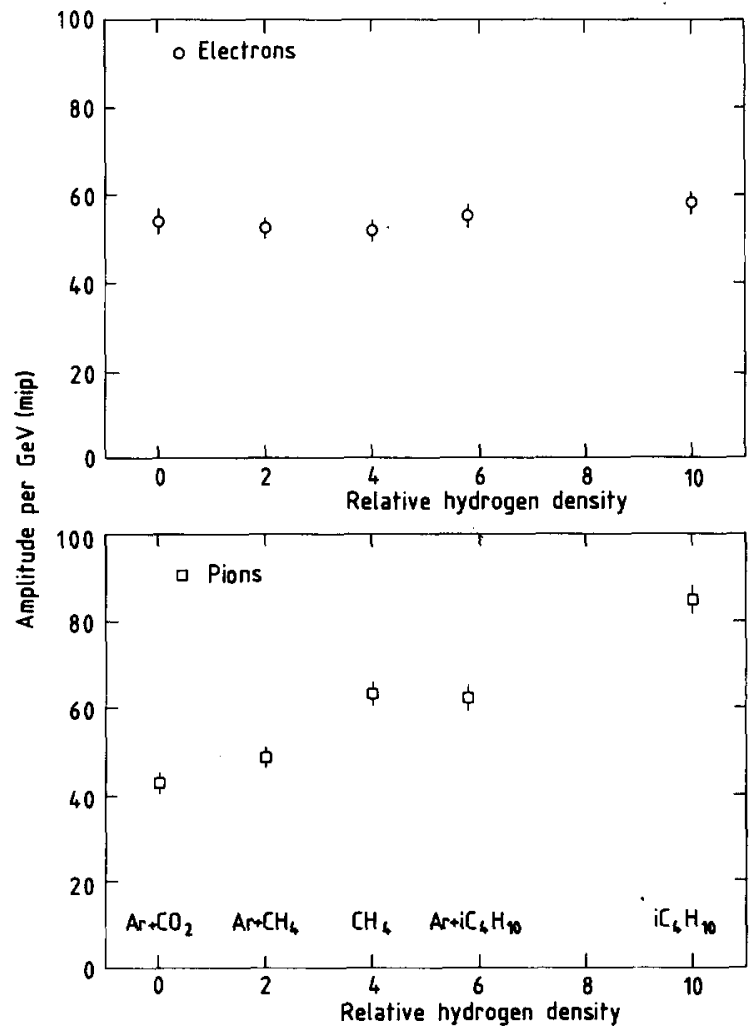

Fig. 20. Gas dependence of the calorimeter response per $\mathrm{GeV}$ to (a) electrons, (b) pions. Slow electronics, $4.5 \mathrm{~mm} \mathrm{U}+1 \mathrm{~mm}$ Cu shielding.

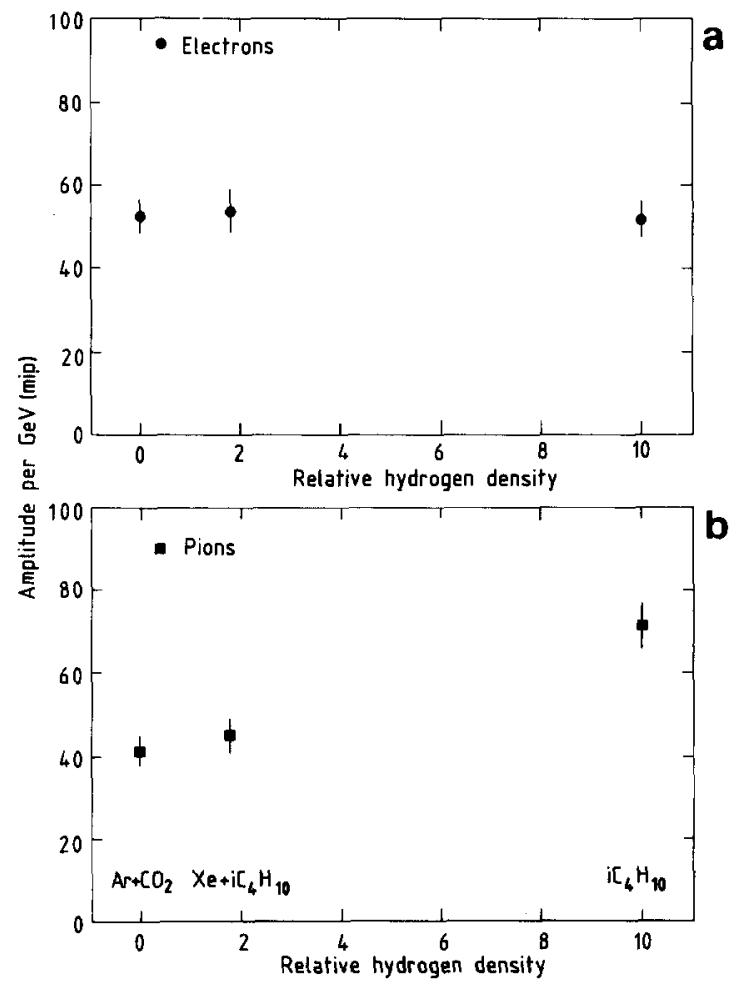

Fig. 21. Gas dependence of the calorimeter response per GeV to (a) electrons, (b) pions. Fast electronics, $4.5 \mathrm{~mm} \mathrm{U}+1 \mathrm{~mm}$ $\mathrm{Cu}$ shielding.

a

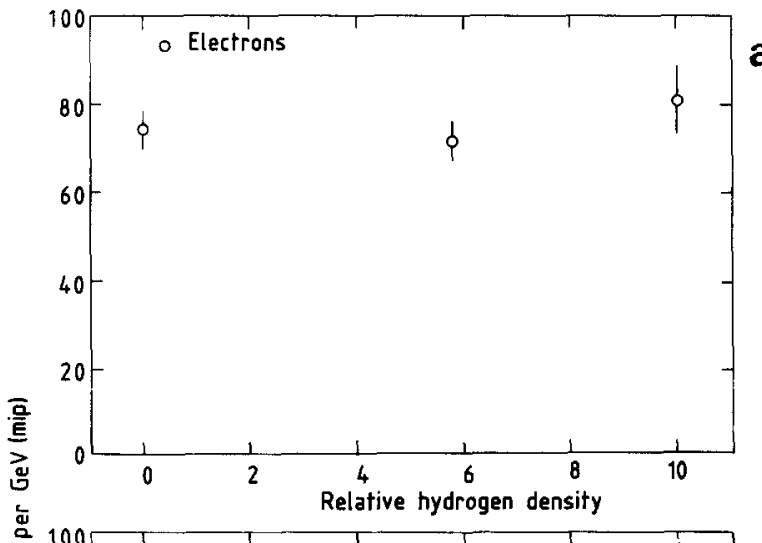

b

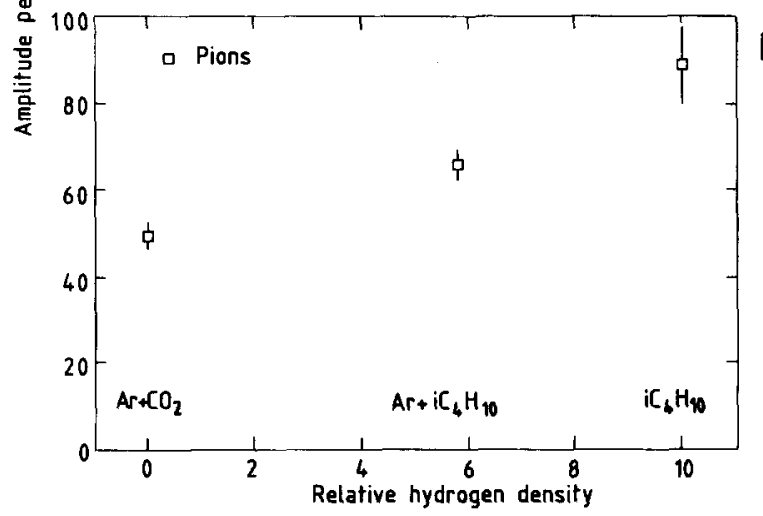

Fig. 22. Gas dependence of the calorimeter response per GeV to (a) electrons, (b) pions. Slow electronics, $4.5 \mathrm{~mm} \mathrm{U}$ without shielding. 


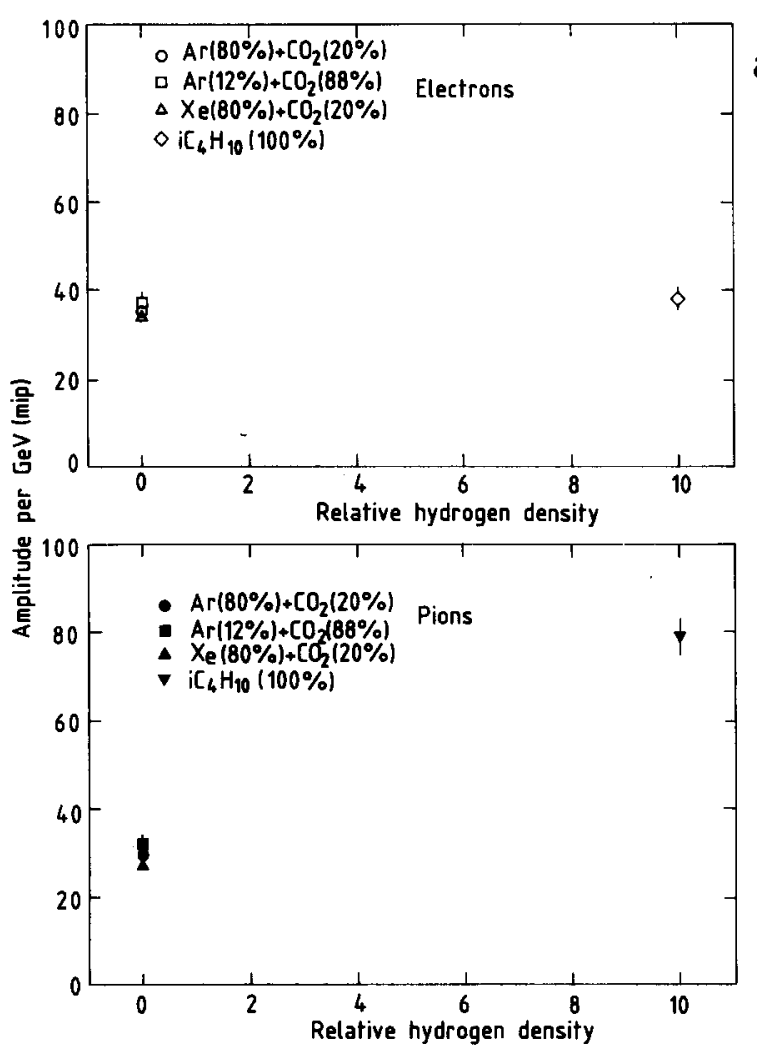

Fig. 23. Gas dependence of the calorimeter response per GeV to (a) electrons, (b) pions. Slow electronics, $9 \mathrm{~mm} \mathrm{U}$ without shielding.

the pion shower. As can be seen in fig. 24, the charge collected in a chamber plane filled with isobutane is approximately twice as large as the one collected with the carbon dioxide filling.

We conclude this section with fig. 25 , which shows

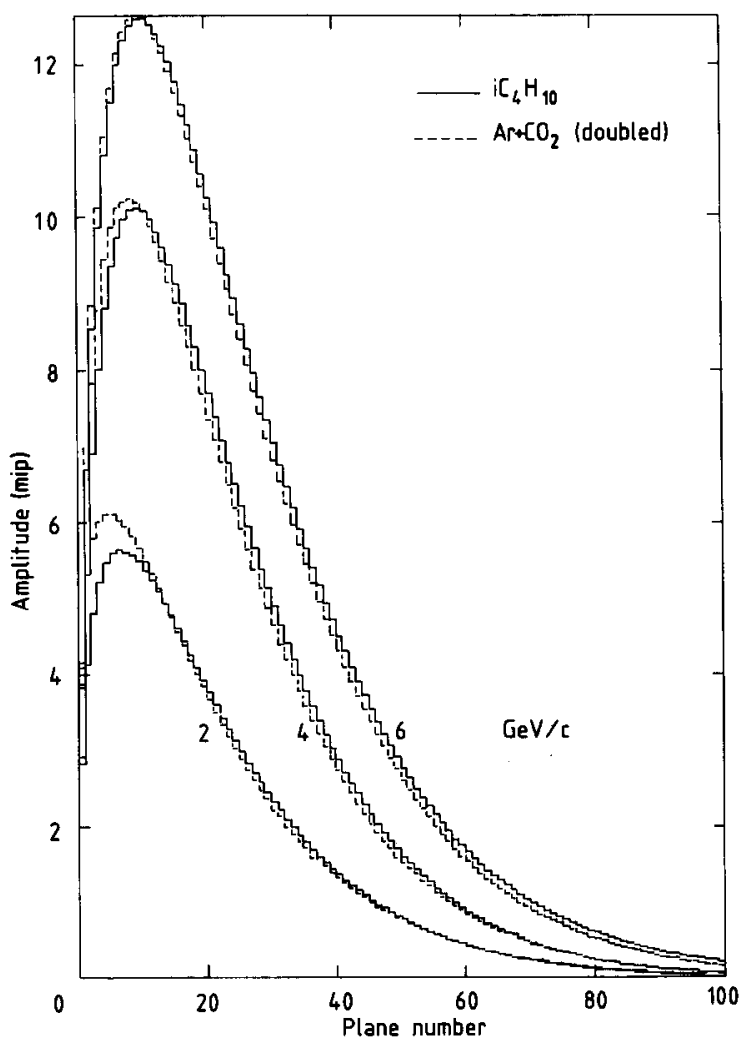

Fig. 24. The longitudinal shower profile for pions. The data for $\mathrm{Ar}+\mathrm{CO}_{2}$ have been multiplied by 2 . For the sake of convenience the smoothed data are given. The structure is $4.5 \mathrm{~mm}$ $\mathrm{U}+1 \mathrm{~mm}$ Cu shielding.

the distribution of the response of a plane containing the maximum ionization in the event. The difference in the behaviour of pions when an isobutane filling or an $\mathrm{Ar}+\mathrm{CO}_{2}$ filling is used is striking.

Table 7

Mean response to pions (mip/GeV); "slow" (“fast”) electronics

\begin{tabular}{|c|c|c|c|c|c|}
\hline \multirow[t]{2}{*}{ Gas [\%] } & \multicolumn{5}{|l|}{ Structure } \\
\hline & $\begin{array}{l}4.5 \mathrm{~mm} \mathrm{U} \\
1.0 \mathrm{~mm} \mathrm{Cu}\end{array}$ & & $\begin{array}{l}4.5 \mathrm{~mm} \mathrm{U} \\
\text { no shielding }\end{array}$ & & $\begin{array}{l}9.0 \mathrm{~mm} \\
\text { no shielding }\end{array}$ \\
\hline $\mathrm{Ar}+\mathrm{CO}_{2}, 80 / 20$ & $42.8 \pm 2.1$ & $(41.2 \pm 3.3)$ & $49.3 \pm 3.0$ & & $29.5 \pm 1.2$ \\
\hline $\mathrm{Ar}+\mathrm{CO}_{2}, 12 / 88$ & & & & & $32.3 \pm 1.9$ \\
\hline $\mathrm{Xe}+\mathrm{CO}_{2}, 80 / 20$ & & & & & $27.2 \pm 1.1$ \\
\hline $\mathrm{Xe}+\mathrm{iC}_{4} \mathrm{H}_{10}, 82 / 18$ & & $(45.0 \pm 3.9)$ & & & \\
\hline $\mathrm{Ar}+\mathrm{CH}_{4}, 50 / 50$ & $48.7 \pm 2.0$ & & & & \\
\hline $\mathrm{CH}_{4}, 100$ & $63.0 \pm 2.5$ & & & & \\
\hline $\mathrm{Ar}+\mathrm{iC}_{4} \mathrm{H}_{10}, 42 / 58$ & $60.5 \pm 3.3$ & & $65.5 \pm 3.8$ & & \\
\hline $\mathrm{iC}_{4} \mathrm{H}_{10}, 100$ & $84.3 \pm 3.6$ & $(71.0 \pm 5.6)$ & $88.3 \pm 8.8$ & $(78.5 \pm 6.2)$ & $78.8 \pm 4.0$ \\
\hline
\end{tabular}


Table 8

Mean ratio of pion to electron response; "slow" ("fast") electronics

\begin{tabular}{|c|c|c|c|c|c|}
\hline \multirow[t]{2}{*}{ Gas [哌] } & \multicolumn{5}{|l|}{ Structure } \\
\hline & $\begin{array}{l}4.5 \mathrm{~mm} \mathrm{U} \\
1.0 \mathrm{~mm} \mathrm{Cu}\end{array}$ & & $\begin{array}{l}4.5 \mathrm{~mm} \mathrm{U} \\
\text { no shielding }\end{array}$ & & $\begin{array}{l}9.0 \mathrm{~mm} \\
\text { no shieldig }\end{array}$ \\
\hline $\mathrm{Ar}+\mathrm{CO}_{2}, 80 / 20$ & $0.79 \pm 0.016$ & $(0.78 \pm 0.024)$ & $0.66 \pm 0.012$ & & $0.84 \pm 0.017$ \\
\hline $\mathrm{Ar}+\mathrm{CO}_{2}, 12 / 88$ & & & & & $0.86 \pm 0.017$ \\
\hline $\mathrm{Xe}+\mathrm{CO}_{2}, 80 / 20$ & & & & & $0.80 \pm 0.018$ \\
\hline $\mathrm{Xe}+\mathrm{iC}_{4} \mathrm{H}_{10}, 82 / 18$ & & $(0.79 \pm 0.024)$ & & & \\
\hline $\mathrm{Ar}+\mathrm{CH}_{4}, 50 / 50$ & $0.92 \pm 0.019$ & & & & \\
\hline $\mathrm{CH}_{4}, 100$ & $1.22 \pm 0.025$ & & & & \\
\hline $\mathrm{Ar}+\mathrm{iC}_{4} \mathrm{H}_{10}, 42 / 58$ & $1.11 \pm 0.022$ & & $0.92 \pm 0.019$ & & \\
\hline $\mathrm{iC}_{4} \mathrm{H}_{10}, 100$ & $1.45 \pm 0.03$ & $(1.38 \pm 0.041)$ & $1.10 \pm 0.022$ & $(1.08 \pm 0.034)$ & $2.09 \pm 0.042$ \\
\hline
\end{tabular}

\section{Discussion}

Before entering upon the discussion, we will summarize the observations made so far

a) The calorimeter response expressed in mip is gas-dependent for pions but not for electrons.

b) The gas dependence is only observed when hydrogen

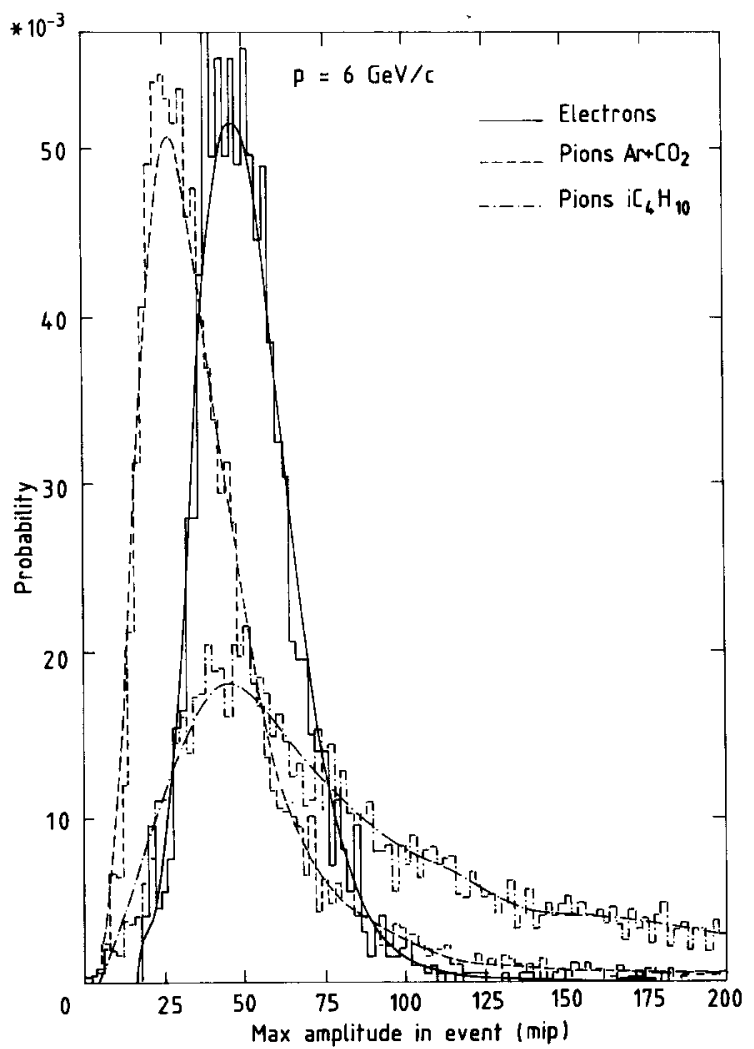

Fig. 25. The distribution of the maximum amplitude detected in an event. The structure is $4.5 \mathrm{~mm} \mathrm{U}+1 \mathrm{~mm} \mathrm{Cu}$ shielding. is present in the gas composition.

c) For hydrogenous gases the calorimeter response to pions becomes much more asymmetric, developing a long "tail" at large amplitudes. Very large ionization deposits in one chamber plane are occasionally observed. These deposits are sometimes comparable to the mean ionization deposited in the entire calorimeter.

d) When the average density of the calorimeter is increased, the effect becomes even more pronounced. It is our belief that the above phenomena can be explained through the contribution of low-energy neutrons arising from the hadronic cascades in uranium.

The picture of the physics processes is qualitatively the following. When a fast hadron interacts with uranium nuclei, some low-energy (evaporation) neutrons are produced. These neutrons have energies of a few $\mathrm{MeV}$ and give rise to uranium fission; the fission process becomes a source of yet more neutrons.

The neutrons are not easily absorbed. They experience mainly elastic scattering in the uranium and lose little energy per interaction. The mean free path for elastic scattering is a few centimetres, whilst the absorption length of neutrons due to $(n, \gamma)$ reactions in the uranium is about $1 \mathrm{~m}$. Also, fast fission becomes significant for neutrons with energies above $1.5 \mathrm{MeV}$, and this serves to produce still more neutrons. Most of the losses occur as a result of leakage of the neutrons out of the sides of the calorimeter. But before they are absorbed or leave the calorimeter they may cross many chamber gaps. Although the probability of neutron interaction in the gas is low, it becomes appreciable when multiplied by the average number of gap crossings.

In scattering off hydrogen in the gas, the neutrons lose a large fraction of their energy to recoil protons. The protons stop in the gas and give rise to a broad spectrum of ionization deposits. These are typically 100 $\mathrm{keV}$ but may reach several $\mathrm{MeV}$. These values should be compared with the few $\mathrm{keV}$ deposited by a relativistic 
particle crossing a chamber plane.

This picture can be illustrated by some Monte Carlo calculations. In these calculations the neutrons were assumed to be prodcued in the uranium absorber with a spallation energy spectrum [6]. The neutrons were transported through the absorber with a Monte Carlo program which took into account the cross sections for different $\mathbf{n}$-nuclei processes (including scattering, fission, capture, etc.), the finite geometry of the experimenal setup, and both transverse and longitudinal distributions of the neutron production point.

The energy spectrum of the neutrons crossing the chamber planes as calculated by this program was used to evaluate the neutron detection probability. The dynamic range of the ADCs was also taken into account. Only elastic neutron scattering with gas constituents was considered. The ranges, $\mathrm{d} E / \mathrm{d} x$, and the cell geometry were taken into account for protons only. Other recoils were assumed to deposit their energy at the interaction point.

Fig. 26 compares neutron detection in isobutane with that in an $\mathrm{Ar}+\mathrm{CO}_{2}$ mixture where the ionization losses of recoil particles are plotted for both gases. The result of the calculations clearly reflects the presence of

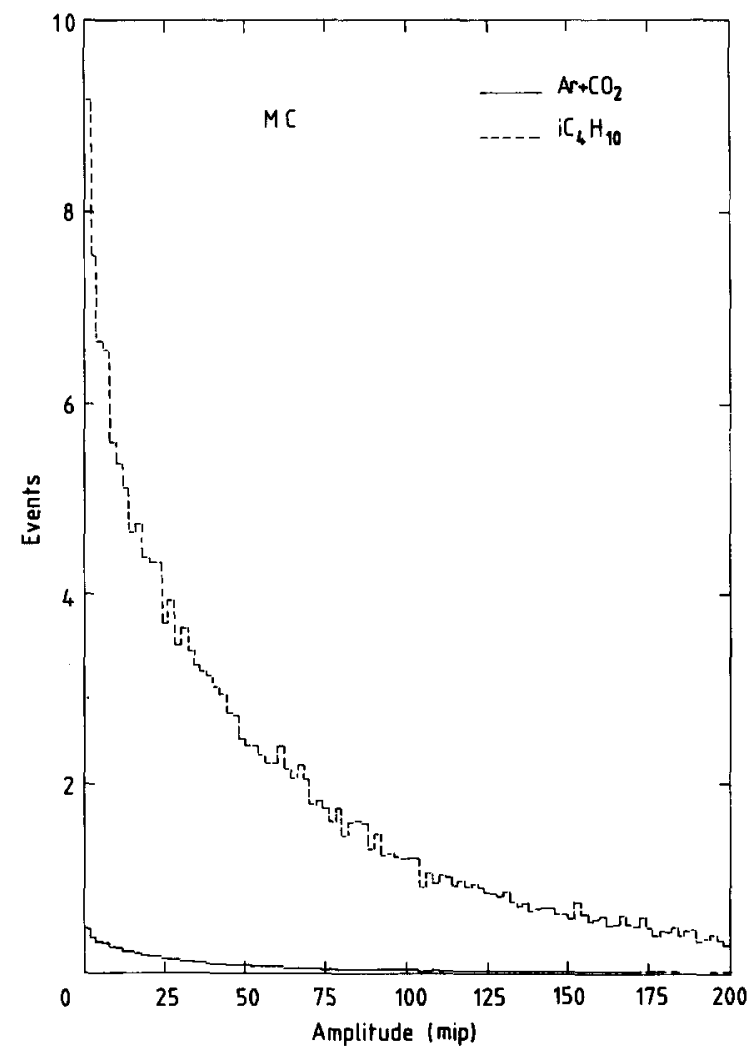

Fig. 26. The ionizaton loss distribution of recoil particles produced in low-energy neutron elastic scattering (Monte Carlo calculation).
Table 9

Neutron detection in a chamber gap (calculated)

\begin{tabular}{lllll}
\hline $\begin{array}{l}\text { Gas composition } \\
{[\%]}\end{array}$ & $\begin{array}{l}\text { Interaction } \\
\text { probability } \\
\text { per crossing }\end{array}$ & $\begin{array}{l}\text { Mean } \\
\text { response } \\
\langle A\rangle \\
{[\mathrm{keV}]}\end{array}$ & $\begin{array}{l}\text { Ionization } \\
\text { deposit } \\
\text { per crossing } \\
W\langle A\rangle \\
{[\mathrm{keV}]}\end{array}$ \\
\hline $\mathrm{Wr}+\mathrm{CO}_{2}$ & $80 / 20$ & $7.51 \times 10^{-5}$ & 88 & 0.0066 \\
$\mathrm{Ar}+\mathrm{CO}_{2}$ & $10 / 90$ & $2.36 \times 10^{-4}$ & 104 & 0.0245 \\
$\mathrm{Xe}+\mathrm{CO}_{2}$ & $80 / 20$ & $7.22 \times 10^{-5}$ & 89 & 0.0064 \\
$\mathrm{iC} \mathrm{H}_{10}$ & 100 & $1.94 \times 10^{-3}$ & 188 & 0.3643 \\
$\mathrm{Ar}+\mathrm{iC}_{4} \mathrm{H}_{10}$ & $42 / 58$ & $1.13 \times 10^{-3}$ & 133 & 0.1506 \\
$\mathrm{Xe} / \mathrm{iC}_{4} \mathrm{H}_{10}$ & $82 / 18$ & $3.69 \times 10^{-4}$ & 161 & 0.0594 \\
$\mathrm{CH}{ }_{4}$ & 100 & $7.27 \times 10^{-4}$ & 114 & 0.0828 \\
$\mathrm{Ar}+\mathrm{CH}_{4}$ & $60 / 40$ & $3.07 \times 10^{-4}$ & 123 & 0.0378 \\
\hline
\end{tabular}

hydrogen in the isobutane; the interaction probability in isobutane is 25 times higher. It can also be seen that whilst the mean ionization deposit produced by a recoil proton is about $60 \mathrm{mip}$, the tail extends well above 200 mip. The results of these calculations are summarized in table 9.

Fig. 27 plots the measured calorimeter response to electrons and pions versus the calculated ionization deposit due to neutrons. It should be noted that the ionization deposit is converted from $\mathrm{keV}$, as given in table 9, into mip, the units of measurement. The procedure of conversion was not trivial. In the following the values of $\mathrm{keV} / \mathrm{mip}$ given in ref. [7] have been used.

In order to estimate the uncertainties involved in the conversion, an evaluation of the muon response in different gases has been performed. The calorimeter response to $2 \mathrm{GeV}$ muons (1 $\mathrm{mip}$ ) was calculated according to ref. [8]. The muon bremsstrahlung, direct electron pair production, as well as delta-ray production in the absorber were considered. The values obtained here differ from those of ref. [7] by 3-20\% and are used to evaluate the uncertainties in the abscissa values in figs. 27 and 28.

The results of calculations for the electron response obtained with the EGS code are also shown in fig. 27. The EGS Monte Carlo code predicts that the ionization is gas-independent and is in satisfactory agreement with our observations. On the other hand, the predicted pion response rises with the increasing ionization induced by neutrons.

One would expect the rise to be linear. However, the errors are too large to be able to claim linearity. One could try to improve the situation by eliminating the systematic error arising from the muon calibration. Since the muon calibration affects the electrons and pions in the same way, and since no gas dependence for electron response is observed, the parameter to plot is the ratio of pion to electron responses. As seen in fig. 28, better linearity is observed. Fig. $28 \mathrm{~b}$ is the corresponding plot 


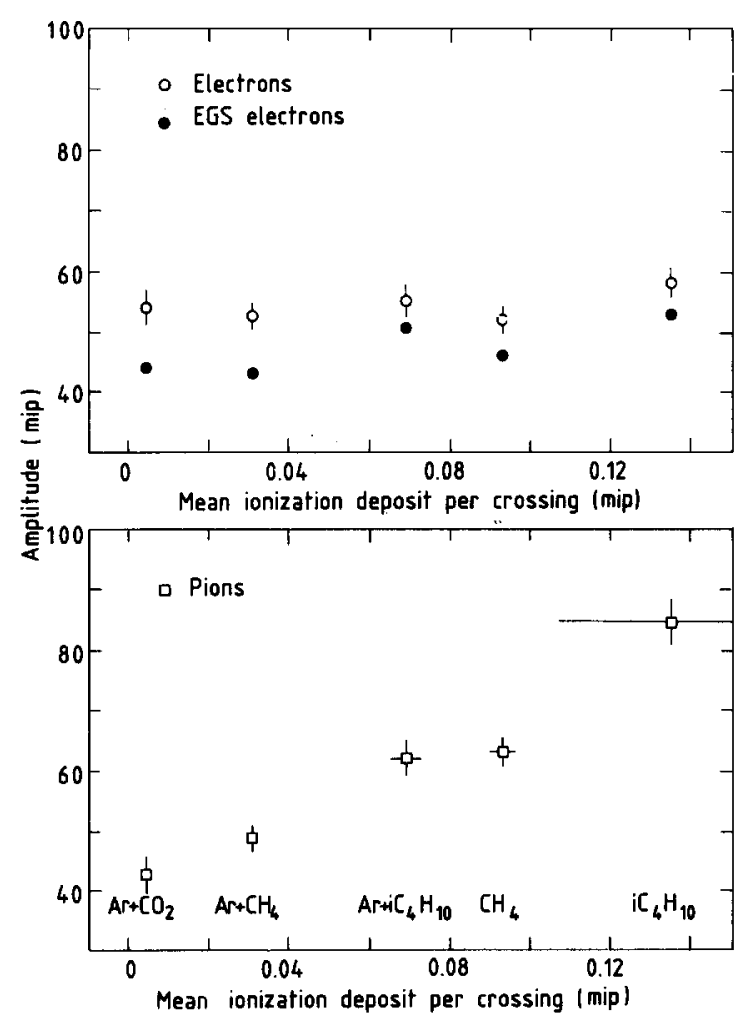

Fig. 27. The calorimeter response (per $\mathrm{GeV}$ ) to pions and electrons vs calculated ionization deposit due to slow neutrons (see text). The EGS Monte Carlo results for electrons are also shown. Data are taken with slow electronics. The structure is $4.5 \mathrm{~mm} \mathrm{U}+1 \mathrm{Cu}$ shielding.

for the data without copper shielding. The result is essentially the same.

The slope of a straight line through the data in fig. $28 \mathrm{a}$ is proportional to the average number of gap crossings per $1 \mathrm{GeV}$ experienced by neutrons responsible for the additional signal. The number of gap crossings is estimated to be about $300 / \mathrm{GeV}$. This figure, combined with the probability of neutron interaction in the gas, e.g. 0.002 for isobutane in table 9 , yields the average number of "spikes" - large ionization deposits produced by the neutrons. In the above example,

$0.002 \times 300=0.6$ "spikes" $/ \mathrm{GeV}$.

As can be seen, the neutron contribution to the calorimeter response is primarily in the form of large, relatively rare signals which are subject to big fluctuations. As a consequence, the calorimeter energy resolution deteriorates whereas the ratio of pion to electron responses can be closer to 1 , thus showing "compensation". This is illustrated in fig. 29, where the calorimeter resolution for pions is plotted versus the ratio of pion to electron responses. The best resolution corresponds to a pion/electron ratio of 0.8 (no hydrogen) rather than the

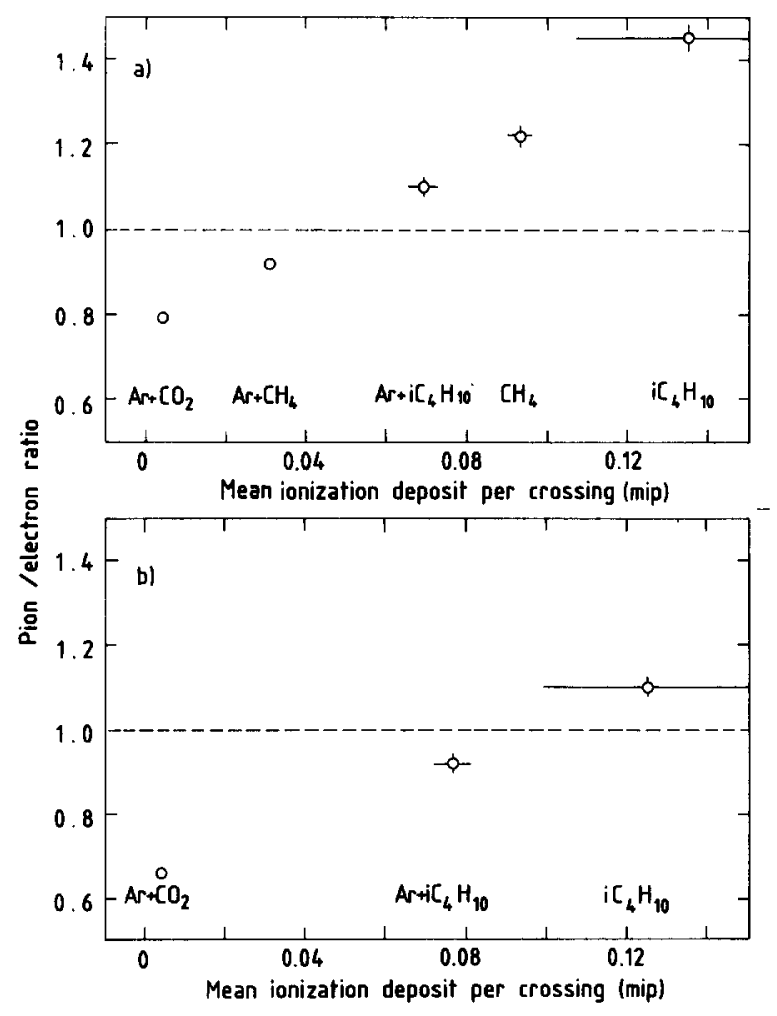

Fig. 28. The pion/electron response ratio vs calculated ionization deposit due to slow neutrons (see text); (a) $4.5 \mathrm{~mm} \mathrm{U}+1$ Cu shielding, (b) 4.5 . $\mathrm{mm} U$ without shielding.

ratio of 1 . This leads to the conclusion that the pion and electron responses can be equalized by simply introducing hydrogen into the gas mixture. However, this will be at the expense of the energy resolution.

When a hydrogenous gas is used, the low-energy neutron contribution manifests itself in the peculiar dependence of the mean pion response on the sampling thickness. As was shown in fig. 23 , when a second 4.5 $\mathrm{mm}$ uranium plate was put in front of every chamber the electron response decreased by approximately a factor of 2 , as one would naturally have expected. On the other hand the pion response showed almost no change. The values taken from table 7 are $88 \mathrm{mip}$ and $79 \mathrm{mip}$ for $4.5 \mathrm{~mm}$ and $9 \mathrm{~mm}$ uranium, respectively. This means that since in the $9 \mathrm{~mm}$ structure for a given total thickness of absorber only half the chambers were used, the signal in a single chamber was almost twice as large as that in the $4.5 \mathrm{~mm}$ structure. This can be seen in fig. 30 .

The above observation is naturally explained by the features of the low-energy neutrons. As mentioned earlier, a large source of loss for neutrons is the leakage out of the sides of the calorimeter, and leakage depends 


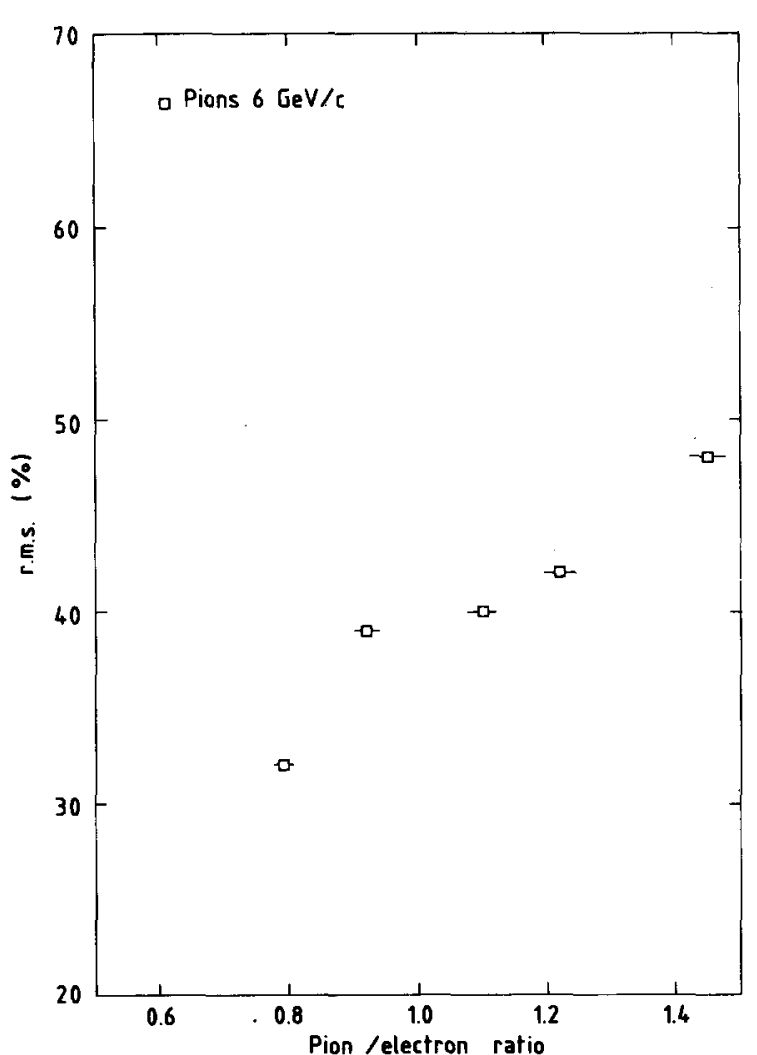

Fig. 29. An example of the dependence of the calorimeter resolution (rms) on the pion/electron response ratio. Data are taken with slow electronics. The structure is $4.5 \mathrm{~mm} \mathrm{U}+1 \mathrm{~mm}$ $\mathrm{Cu}$ shielding.

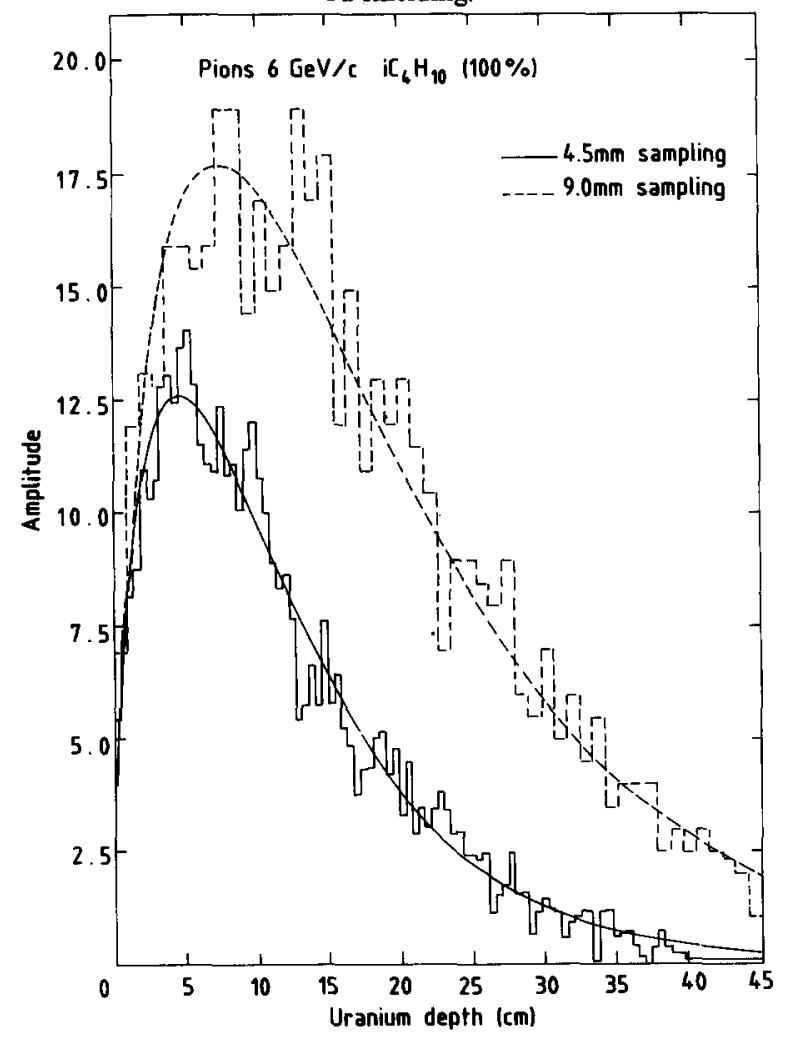

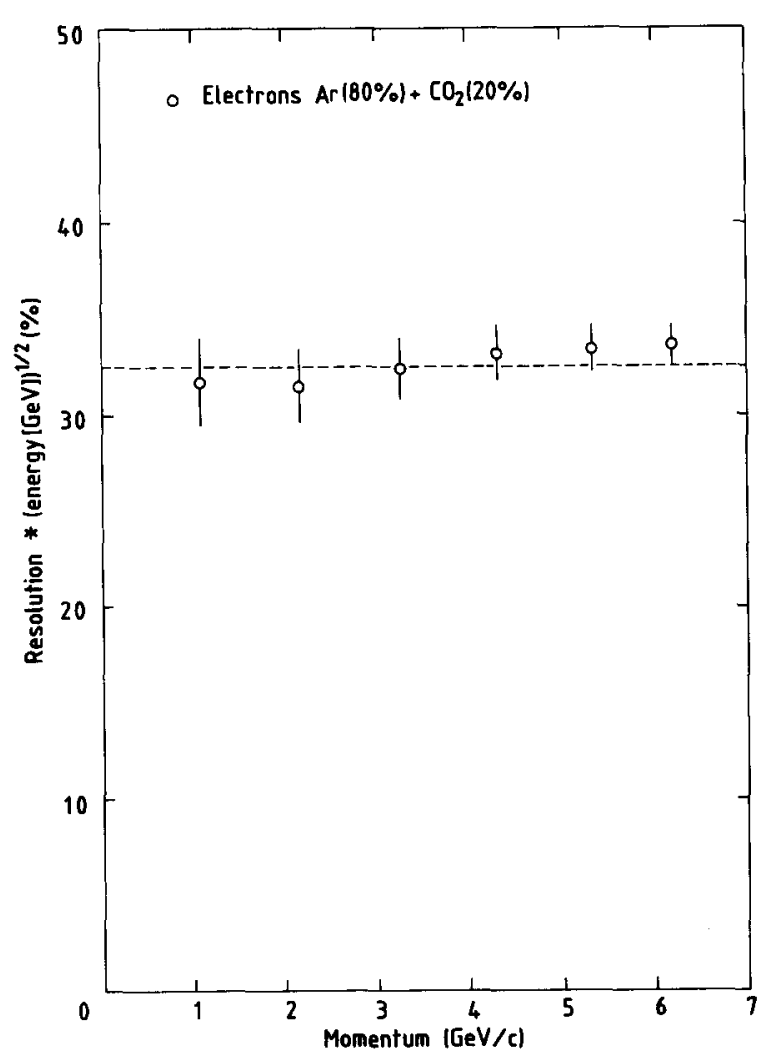

Fig. 31. The energy dependence of the resolution of the uranium gas calorimeter for electrons. The gas mixture is $\mathrm{Ar}+\mathrm{Co}_{2}$. Plotted on the ordinate is the resolution (Gaussian fit) multiplied by the square root of energy. Data are taken with slow electronics. The structure is $4.5 \mathrm{~mm} \mathrm{U}+1 \mathrm{~mm} \mathrm{Cu}$ shielding.

on the effective calorimeter density and the surface out of which the neutrons can escape. When one more uranium plate was put in front of every chamber, the density of the calorimeter was effectively increased, and accordingly the neutron signal became stronger.

This simple explanation was confirmed by a Monte Carlo calculation of neutron transport through the calorimeter structure. The detailed comparison will be published later.

For completeness the measured calorimeter resolution ${ }^{*}$ for the $\operatorname{Ar}(80 \%)+\mathrm{CO}_{2}(20 \%)$ mixture is given in figs. 31 and 32 as a function of the incident momentum for electrons and pions.

* The resolution is determined by a Gaussian fit of the calorimeter response. No uranium noise subtraction was made.

Fig. 30. The longitudinal shower development measured with two different values of sampling thickness: $4.5 \mathrm{~mm} U$ and 9 $\mathrm{mm}$ U. Data are taken with slow electronics. The curves are plotted to guide the eye. 


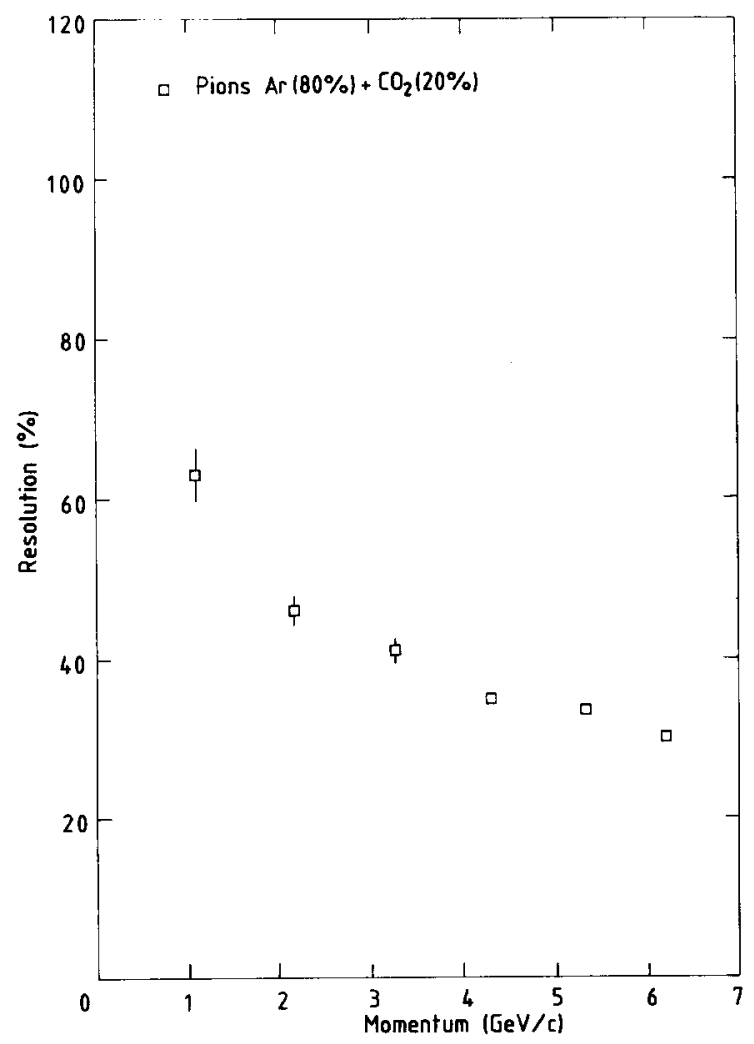

Fig. 32. The energy dependence of the resolution of the uranium gas calorimeter for pions. The gas mixture is $\mathrm{Ar}+\mathrm{CO}_{2}$. Plotted on the ordinate is the resolution (Gaussian fit). Data are taken with slow electronics. The structure is $4.5 \mathrm{~mm} \mathrm{U}+1 \mathrm{~mm} \mathrm{Cu}$ shielding.

\section{Conclusions}

We have built and tested a variable-structure uranium sampling calorimeter with proportional chamber readout.

The calorimeter response to electrons does not depend on the gas used for the chamber filling. When the sampling thickness is changed, the resolution and the response of the uranium calorimeter to electrons vary in the same way as for a conventional (non-uranium) calorimeter.

The calorimeter response to pions depends strongly on the hydrogen content of the gas inside the chambers.

The effect is understood to originate from the lowenergy neutrons produced in hadronic showers. The leakage of the neutrons through the sides of the calorimeter leads to a peculiar dependence of the pion response on the sampling thickness.

The increase of the pion signal and consequently the equalization of the pion and electron responses - "compensation" - does not lead to any improvement in the energy resolution of the calorimeter. This is natural owing to the high amplitude, low statistics character of the neutron-induced signals.

\section{Acknowledgements}

We are very grateful to Prof. A.D. Galanin and Dr. P.P. Blagovolin for very useful discussions on neutron behaviour, and to Dr. L.A. Myrtzymova and Dr. V.D. Kazaritsky for their help in Monte Carlo calculations.

We would also like to thank Dr. P. Lecomte for his assistance in the experiment and Mr. H. Schick for his help in the instrumentation of the calorimeter.

The University of Michigan authors (T.A., R.C.B., I.D.L., and M.J.L.) wish to acknowledge the support of the US National Science Foundation.

\section{References}

[1] A. Arefiev et al., Nucl. Instr. and Meth. A245 (1986) 71.

[2] A. Arefiev et al., report ITEP-150 (1983).

[3] F. Celletti et al., Nucl. Instr. and Meth. 225 (1984) 493.

[4] P. Gorbunov et al., report ITEP-38 (1983).

[5] R.C. Ball et al., Nucl. Instr. and Meth. 197 (1982) 371.

[6] T.W. Armstrong et al., Nucl. Instr. and Meth. 222 (1984) 540.

[7] F. Sauli, CERN 77-09 (1977).

[8] W. Lohmann et al., CERN 85-03 (1985); R.M. Steinheimer et al., At. Data Nucl. Data Tables 30 (1984) 261.

[9] R.L. Ford and W.R. Nelson, SLAC-210 (1978). 